\title{
Estimating precipitation susceptibility in warm marine clouds using multi-sensor aerosol and cloud products from A-Train satellites
}

\author{
Heming Bai ${ }^{1,2}$, Cheng Gong ${ }^{3}$, Minghuai Wang ${ }^{1,2}$, Zhibo Zhang ${ }^{4}$, and Tristan L'Ecuyer ${ }^{5}$ \\ ${ }^{1}$ Institute for Climate and Global Change Research and School of Atmospheric Sciences, Nanjing University, Nanjing, China \\ ${ }^{2}$ Collaborative Innovation Center of Climate Change, Jiangsu, China \\ ${ }^{3}$ Institute of Atmospheric Physics, Chinese Academy of Science, Beijing, China \\ ${ }^{4}$ Physics Department, University of Maryland Baltimore County (UMBC), Baltimore, MD, USA \\ ${ }^{5}$ Department of Atmospheric and Oceanic Sciences, University of Wisconsin, Madison, WI, USA
}

Correspondence: Minghuai Wang (minghuai.wang@nju.edu.cn)

Received: 23 September 2017 - Discussion started: 12 October 2017

Revised: 9 December 2017 - Accepted: 3 January 2018 - Published: 7 February 2018

\begin{abstract}
Precipitation susceptibility to aerosol perturbation plays a key role in understanding aerosol-cloud interactions and constraining aerosol indirect effects. However, large discrepancies exist in the previous satellite estimates of precipitation susceptibility. In this paper, multi-sensor aerosol and cloud products, including those from the CloudAerosol Lidar and Infrared Pathfinder Satellite Observation (CALIPSO), CloudSat, Moderate Resolution Imaging Spectroradiometer (MODIS), and Advanced Microwave Scanning Radiometer for the Earth Observing System (AMSRE) from June 2006 to April 2011 are analyzed to estimate precipitation frequency susceptibility $S_{\mathrm{POP}}$, precipitation intensity susceptibility $S_{\mathrm{I}}$, and precipitation rate susceptibility $S_{\mathrm{R}}$ in warm marine clouds. We find that $S_{\mathrm{POP}}$ strongly depends on atmospheric stability, with larger values under more stable environments. Our results show that precipitation susceptibility for drizzle (with a $-15 \mathrm{dBZ}$ rainfall threshold) is significantly different than that for rain (with a $0 \mathrm{dBZ}$ rainfall threshold). Onset of drizzle is not as readily suppressed in warm clouds as rainfall while precipitation intensity susceptibility is generally smaller for rain than for drizzle. We find that $S_{\mathrm{POP}}$ derived with respect to aerosol index (AI) is about one-third of $S_{\mathrm{POP}}$ derived with respect to cloud droplet number concentration (CDNC). Overall, $S_{\mathrm{POP}}$ demonstrates relatively robust features throughout independent liquid water path (LWP) products and diverse rain products. In contrast, the behaviors of $S_{\mathrm{I}}$ and $S_{\mathrm{R}}$ are subject to LWP or rain products used to derive them. Recommendations are further
\end{abstract}

made for how to better use these metrics to quantify aerosolcloud-precipitation interactions in observations and models.

\section{Introduction}

Aerosol-cloud interactions play an important role in the climate system and affect the global energy budget and hydrological cycle. The effective radiative forcing from aerosolcloud interactions (ERFaci), which includes the instantaneous effect on cloud albedo from changes in cloud condensation nuclei $(\mathrm{CCN})$ or ice nuclei and all subsequent changes to cloud lifetime and thermodynamics, remains one of the largest uncertainties in our estimates of anthropogenic radiative forcing (Boucher et al., 2013). Over the past few decades, numerous methodologies have been developed to understand and quantify the impacts of aerosol-cloud interactions on the climate system. A unique method is to use the so-called "susceptibility" to explain and predict how clouds and precipitation would respond if there were some aerosol perturbations. Susceptibility is defined as the derivative of cloud and/or precipitation properties with respect to aerosolrelated properties. For example, Platnick and Twomey (1994) proposed a cloud albedo susceptibility as $S_{\lambda}=\partial A / \partial \mathrm{CDNC}$, where $A$ is cloud albedo and CDNC is cloud droplet number concentration, to quantify the cloud albedo effect of aerosol.

Precipitation susceptibility has been proposed to evaluate aerosol-cloud-precipitation interactions and to further constrain the cloud water response to aerosol perturbations in cli- 
mate models (Feingold and Siebert, 2009; Terai et al., 2012; Wang et al., 2012). It was first proposed by Feingold and Siebert (2009) and was defined as

$S_{0}=-\frac{\mathrm{d} \ln R}{\mathrm{~d} \ln \mathrm{CDNC}}$,

where $R$ is precipitation intensity (precipitation rate for rainy clouds) and CDNC is cloud droplet number concentration (Feingold and Siebert, 2009). Sorooshian et al. (2009) further estimated $S_{0}$ by replacing CDNC with aerosol index (AI). Wang et al. (2012) proposed an alternative metric, the precipitation frequency susceptibility, defined as

$S_{\mathrm{POP}}=-\frac{\mathrm{d} \ln \mathrm{POP}}{\mathrm{d} \ln \mathrm{AI}}$,

where POP is the probability of precipitation. $S_{\mathrm{POP}}$ has been shown to strongly correlate with cloud water response to aerosol perturbations in global climate models (Wang et al., 2012; Ghan et al., 2016). Terai et al. $(2012,2015)$ further extended the definition of precipitation susceptibility:

$S_{\mathrm{X}}=-\frac{\mathrm{d} \ln X}{\mathrm{~d} \ln \mathrm{CDNC}}$,

where $X$ can represent precipitation intensity ( $I$, precipitation rate from rainy clouds only), precipitation fraction (POP or $f)$ or precipitation rate $(R=\mathrm{POP} \times I$, mean precipitation rate from both rainy and non-rainy clouds). Depending on whether $I$, POP, or $R$ are used in Eq. (3), precipitation intensity susceptibility $\left(S_{\mathrm{I}}\right)$, precipitation frequency susceptibility $\left(S_{\mathrm{POP}}\right.$ or $\left.S_{\mathrm{f}}\right)$, or precipitation rate susceptibility $\left(S_{\mathrm{R}}\right)$ are therefore defined accordingly. Since $R$ can be decomposed into the product of POP and $I, S_{\mathrm{R}} \approx S_{\mathrm{POP}}+S_{\mathrm{I}}$ (Terai et al., 2012, 2015). In addition, some other studies substitute aerosol concentration $\left(N_{\mathrm{A}}\right)$ or cloud condensation nuclei $(\mathrm{CCN})$ concentration $\left(N_{\mathrm{CCN}}\right)$ for CDNC to calculate $S_{\mathrm{X}}$ (Terai et al., 2012; Mann et al., 2014).

The behavior and magnitude of aforementioned precipitation susceptibility metrics varies a lot in different studies. For instance, $S_{\mathrm{R}}$ and $S_{\mathrm{POP}}$, using $N_{\mathrm{A}}$ as an aerosol proxy from Terai et al. (2012), both noticeably decrease with increasing LWP, whereas $S_{\mathrm{I}}$ is flat in the same study. Additionally, previous satellite studies (Wang et al., 2012; Terai et al., 2015; Michibata et al., 2016) show $S_{\mathrm{X}}$ calculated with respect to CDNC is higher than that with respect to AI. The diverse definitions of precipitation susceptibility make it challenging to understand susceptibility discrepancies in different studies. An important objective of this study is to derive these susceptibilities using the same observations in the same context and to better understand their differences through comparisons.

Another source of uncertainty in the estimation of precipitation susceptibility is the uncertainty associated with the observation. Among many others, the Advanced Microwave Scanning Radiometer for the Earth Observing System (AMSR-E) and Moderate Resolution Imaging Spectro- radiometer (MODIS) are two widely used satellite cloud retrieval products in aerosol-cloud interaction studies. For instance, Sorooshian et al. (2009) and Wang et al. (2012) both used the AMSR-E LWP product to estimate $S_{\mathrm{I}}$ and $S_{\mathrm{POP}}$ with respect to AI, respectively. Terai et al. (2015) and Michibata et al. (2016) used the MODIS LWP product to estimate $S_{\text {I }}$ with respect to CDNC. Both products have their advantages and limitations, and are both subject to various retrieval uncertainties. AMSR-E has a coarser spatial resolution than MODIS. Its LWP retrievals are available for both daytime and nighttime but suffer from instrument noise, cloud detection issues, and beam filling effect (Greenwald et al., 2007; Horváth and Gentemann, 2007; Seethala and Horváth, 2010). MODIS LWP retrievals are available only during daytime. The main uncertainty sources in MODIS LWP retrievals include instrument noise, subpixel cloud inhomogeneity, threedimensional radiative effects, and uncertainties in ancillary data (Cho et al., 2015; Platnick et al., 2017; Zhang and Platnick, 2011). A recent study by Seethala and Horváth (2010) revealed several significant differences between AMSR-E and MODIS LWP products, which could contribute to the aforementioned discrepancy of precipitation susceptibility in the literature.

Additionally, different definitions of rain events and/or different methods to derive rain rates could also lead to discrepancy in observation-based estimation of precipitation susceptibility. For example, the rain rate used in Terai et al. (2015) and Michibata et al. (2016) is simply estimated based on a $Z$ $R$ relationship from CloudSat radar reflectivity profile measurements. In contrast, Sorooshian et al. (2009) and Wang et al. (2012) used the rain rate reported in the CloudSat operational product, which makes use not only of radar reflectivity but also path-integrated attenuation in the retrieval process (Haynes et al., 2009). The primary satellite data sets used in the previous studies for estimating precipitation susceptibility are listed in Table 1. To account for the discrepancy in susceptibility as shown in Table 1, it is important to examine how different LWP and rain data sets affect the estimates of precipitation susceptibility.

Here, we estimate precipitation susceptibility using multisensor cloud and aerosol products from A-Train satellites. The main objective of this study is to compare precipitation susceptibility estimates based on different retrieval products, and to better understand discrepancies documented in previous studies. As previous studies have shown that aerosol indirect effect and its uncertainties vary in different cloud dynamical regimes (L'Ecuyer et al., 2009; Wang et al., 2012; Zhang et al., 2016), we further examine how precipitation susceptibility might be different under different atmospheric stability conditions. Section 2 introduces different satellite products and methods used to calculate the susceptibility; Sect. 3 compares precipitation susceptibility estimates from different satellite products and explores how atmospheric stability affects precipitation susceptibility; finally, the discussions are made in Sect. 4, followed by the summary in Sect. 5 . 
Table 1. The summary of previous satellite studies for estimating precipitation susceptibility.

\begin{tabular}{|c|c|c|c|c|c|}
\hline Studies & $\begin{array}{l}\text { Rain } \\
\text { variables }\end{array}$ & $\begin{array}{l}\text { Aerosol } \\
\text { proxies }\end{array}$ & Thresholds & Behavior & $\begin{array}{l}\text { Satellite } \\
\text { data sets }\end{array}$ \\
\hline $\begin{array}{l}\text { Sorooshian } \\
\text { et al. (2009) }\end{array}$ & $I$ & $\mathrm{AI}$ & Surface $1 \mathrm{mmh}^{-1}$ & $S_{\mathrm{I}}: \nearrow \searrow$ & $\begin{array}{l}\text { 2C-PRECIP-COLUMN } \\
\text { AMSR-E L2B-Ocean } \\
\text { MYD08-D3 }\end{array}$ \\
\hline $\begin{array}{l}\text { Wang et al. } \\
(2012)\end{array}$ & POP & AI & Rain certain $^{\mathrm{a}}$ & $S_{\mathrm{POP}}<0.2$ & $\begin{array}{l}\text { 2C-PRECIP-COLUMN } \\
\text { AMSR-E L2B-Ocean } \\
\text { MYD08-D3 }\end{array}$ \\
\hline $\begin{array}{l}\text { Terai et al. } \\
\text { (2015) }\end{array}$ & $R / \mathrm{POP} / I$ & CDNC & $-15 \mathrm{dBZ}$ of $Z_{\max }{ }^{b}$ & $\begin{array}{l}S_{\mathrm{R}}: \searrow \\
S_{\mathrm{POP}}: \searrow \\
S_{\mathrm{I}}: \nearrow\end{array}$ & $\begin{array}{l}\text { 2B-GEOPROF } \\
\text { MYD06_L2 }\end{array}$ \\
\hline $\begin{array}{l}\text { Michibata } \\
\text { et al. (2016) }\end{array}$ & $I$ & CDNC & $-15 \mathrm{dBZ}$ of $Z_{\max }^{\mathrm{b}}$ & $S_{\mathrm{I}}: \nearrow \searrow$ & $\begin{array}{l}\text { 2B-GEOPROF } \\
\text { MYD06_L2 }\end{array}$ \\
\hline
\end{tabular}

a "Rain certain" is a flag of the 2C-PRECIP-COLUMN product, which is equivalent to greater than the attenuation-corrected reflectivity threshold of $0 \mathrm{dBZ}$.

${ }^{\mathrm{b}} Z_{\max }$ : the maximum column radar reflectivity from the 2B-GEOPROF product. The symbols $\nearrow(\searrow$ ) represent the increasing (decreasing) trend of susceptibility with increasing LWP.

Table 2. Satellite products employed to estimate aerosol and cloud properties in this study.

\begin{tabular}{|c|c|c|c|c|c|}
\hline Parameter & Product & Subset & $\begin{array}{l}\text { Horizontal } \\
\text { resolution }\end{array}$ & Sensor & Satellite \\
\hline \multirow[t]{3}{*}{ AI } & MYD08_D3 & $\begin{array}{l}\text { Aerosol_Optical_Depth_Land_Ocean_Mean } \\
\text { Aerosol_AE1_Ocean_JHisto_vs_Opt_Depth }\end{array}$ & $1^{\circ}$ & MODIS & Aqua \\
\hline & MYD04_L2 & $\begin{array}{l}\text { Optical_Depth_Land_And_Ocean } \\
\text { Angstrom_Exponent_1_Ocean }\end{array}$ & $10 \mathrm{~km}$ & & \\
\hline & CAL_LID_L2_05kmALay & $\begin{array}{l}\text { Column_Optical_Depth_Aerosol_532 } \\
\text { Column_Optical_Depth_Aerosols_1064 }\end{array}$ & $5 \mathrm{~km}$ & CALIOP & CALIPSO \\
\hline CDNC/LWP & MYD06_L2 ${ }^{\mathrm{a}}$ & $\begin{array}{l}\text { Cloud_Effective_Radius } \\
\text { Cloud_Optical_Thickness }\end{array}$ & $5 \mathrm{~km}$ & MODIS & Aqua \\
\hline LWP & AE_Ocean_L2B & High_res_cloud & $12 \mathrm{~km}$ & AMSR-E & Aqua \\
\hline \multirow[t]{3}{*}{$\mathrm{POP} / R$} & 2B-GEOPROF ${ }^{\mathrm{a}}$ & $\begin{array}{l}\text { CPR_Cloud_mask } \\
\text { Radar_Reflectivity }\end{array}$ & $5 \mathrm{~km}$ & CPR & CloudSat \\
\hline & 2C-PRECIP-COLUMN & $\begin{array}{l}\text { Precip_rate } \\
\text { Precip_flag }\end{array}$ & $1.4 \mathrm{~km} \times 1.7 \mathrm{~km}$ & & \\
\hline & 2C-RAIN-PROFILE & $\begin{array}{l}\text { Rain_rate } \\
\text { Precip_flag }\end{array}$ & & & \\
\hline
\end{tabular}

\section{Methods}

\subsection{Satellite data sets}

This study mainly uses cloud and aerosol property retrieval products from MODIS on Aqua, AMSR-E on Aqua, the Cloud Profiling Radar (CPR) on CloudSat and the CloudAerosol Lidar with Orthogonal Polarization (CALIOP) on the Cloud-Aerosol Lidar and Infrared Pathfinder Satellite Observation (CALIPSO). All of these satellites operate in the framework of the A-Train constellation (L'Ecuyer and
Jiang, 2010; Stephens et al., 2002). Considering most of the warm rainfall occurs in the marine areas (Mülmenstädt et al., 2015) and that satellite retrievals often suffer large uncertainties in the polar regions (Seethala and Horváth, 2010), the study region is limited to $60^{\circ} \mathrm{S}$ to $60^{\circ} \mathrm{N}$ over global oceans, covering the period June 2006 to April 2011. Since MODIS cloud LWP retrieval is only available for daytime, we restrict our analysis to clouds observed in daytime (13:30 LT). The MODIS cloud product and CPR radar reflectivity observations used in this study are both provided from the caltrack 
data sets, which resample observations from many sensors under CALIOP subtrack with the horizontal resolution of $5 \mathrm{~km}$ (see http://www.icare.univ-lille1.fr/projects/calxtract/ products for more information). For other aerosol and cloud products, including MODIS/CALIOP aerosol products and AMSR-E cloud products, they are further collocated into the CALIOP subtracks in the caltrack data set. For each cloud pixel in the caltrack data set, the closest aerosol/cloud retrieval sample within a $1^{\circ}$ grid box $\left(1^{\circ} \times 1^{\circ}\right)$ centered at this caltrack cloud pixel is chosen. To reduce the uncertainty in cloud retrievals, only samples where MODIS cloud fraction is equal to $100 \%$ are selected. The main satellite data sets used in this study are briefly listed in Table 2 .

\subsubsection{AI and CDNC}

Three aerosol products are used in the study: the MODIS Level 3 daily mean atmosphere product (MYD08_D3, Collection 6), MODIS Level 2 aerosol product (MYD04_L2, Collection 6), and CALIOP Level 2 aerosol layer product (CAL_LID_L2_05kmALay, Version 3.01). The $1^{\circ}$ daily mean product of MYD08_D3 is aggregated from MYD04_L2 with $10 \mathrm{~km}$ horizontal resolution (Hubanks et al., 2016). This MODIS Level 3 data set has been used in previous studies to examine aerosol-cloud-precipitation interactions (e.g., L'Ecuyer et al., 2009; Wang et al., 2012) and is compared here with results from the MODIS Level 2 aerosol product to examine how aerosol homogeneity might affect precipitation susceptibility estimates. The horizontal resolution of column aerosol optical depth from the CAL_LID_L2_05kmALay product is $5 \mathrm{~km}$. Aerosol property in this data set is obtained by averaging the 16 aerosol extinction profiles with $333 \mathrm{~m}$ of native resolution along track (Young and Vaughan, 2009).

Since AI is a better proxy for CCN concentrations as compared to AOD (Nakajima et al., 2001), AI is calculated as one of the proxies for $\mathrm{CCN}$ based on the definition of $\mathrm{AI}=\mathrm{AOD} \times \mathrm{AE}$, where $\mathrm{AOD}$ and $\mathrm{AE}$ are aerosol optical depth and the Ångström coefficient, respectively. For MODIS, AODs at $0.55 \mu \mathrm{m}$ reported from MYD08_D3 and MYD04_L2 products are based on the Dark Target algorithm over the ocean (Kaufman et al., 1997; Tanré et al., 1997; Levy et al., 2013). For CALIOP, AOD at wavelength of $0.532 \mu \mathrm{m}$ is obtained from the CAL_LID_L2_05kmALay product (Vaughan et al., 2004). Unlike MODIS AE, which is directly reported in aerosol products, AE measurement for CALIOP is calculated based on AOD at 1.064 and $0.532 \mu \mathrm{m}$ from the CAL_LID_L2_05kmALay product (Bréon et al., 2011). Our data screening for CAL_LID_L2_05kmALay follows a previous study by Kim et al. (2013).

Three aerosol products used in this study are listed in Table 2. It should be noted that all aerosol samples are under cloud-free conditions and are selected in close proximity to cloud pixels. Retrievals of aerosol properties from passive sensors and lidar observation are both affected by clouds near the aerosol, and thereby result in overestimation for aerosol properties (Chand et al., 2012; Christensen et al., 2017; Tackett and Di Girolamo, 2009). The extent of this overestimation may be different among different sensors and depends on how far aerosol pixels are chosen from the corresponding cloud pixels (Christensen et al., 2017). This effect, however, would likely impact all metrics in a similar way and we would not expect this effect to impact qualitative comparisons between different metrics.

CDNC is derived from the cloud optical thickness $\tau$ and cloud top effective radius $r_{\text {eff }}$, both reported in the MODIS Level 2 cloud product (namely, MYD06_L2), based on the following formula (Bennartz, 2007; Quaas et al., 2006):

$\mathrm{CDNC}=\alpha \tau^{0.5} r_{\mathrm{eff}}^{-2.5}$,

where the coefficient $\alpha=1.37 \times 10^{-5} \mathrm{~m}^{-0.5}$ is estimated based on the assumption that cloud vertical structure follows the classic adiabatic growth model (Quaas et al., 2006). To reduce the uncertainty when deriving CDNC, cloud pixels (identified by the caltrack-MODIS cloud product with the horizontal resolution of $5 \mathrm{~km}$ ) where cloud optical depth is less than 3 and cloud fraction is less than $100 \%$ are excluded (Cho et al., 2015; Zhang and Platnick, 2011). Additionally, we limit our analysis to warm clouds by screening cloud pixels with cloud top temperature warmer than $273 \mathrm{~K}$. Under these screening criteria, our results show that $94 \%$ of warm clouds are single layered (93\% in Kubar et al., 2009). Therefore, our analysis mainly focuses on single-layer clouds.

\subsubsection{LWP}

Cloud LWP for MODIS is diagnosed from solar reflectance observations of $r_{\text {eff }}$ and $\tau$ as (Platnick et al., 2003)

$\mathrm{LWP}=a \rho_{\mathrm{w}} \tau r_{\mathrm{eff}}$,

where $\rho_{\mathrm{w}}$ denotes the liquid water density and $a$ is a constant determined by the assumed vertical variation in cloud droplet size (Greenwald, 2009). For a vertically homogeneous cloud, $a=2 / 3$ (Bennartz, 2007), and $a=5 / 9$ when the adiabatic assumption is applied (Szczodrak et al., 2001). A recent study by Miller et al. (2016) provides a systematic investigation of the impacts of cloud vertical structure on MODIS LWP retrievals. To be consistent with the adiabatic assumption used in Eq. (4) for estimating CDNC, $a=5 / 9$ is applied here.

The other LWP retrieval comes from the AMSR-E Level 2B Global Swath Ocean Product (Wentz and Meissner, 2004). Unlike retrieving from solar reflectance of visible near-infrared (VNIR) for MODIS, LWP for AMSR-E is directly derived from brightness temperatures based on liquid-sensitive $37 \mathrm{GHz}$ channel measurements (Seethala and Horváth, 2010). More information on the retrieval technique of AMSR-E LWP is documented in Wentz and Meissner (2000). Horizontal resolution of the AMSR-E LWP prod- 
uct $(12 \mathrm{~km})$ is also different from the MODIS LWP product $(5 \mathrm{~km})$.

\subsubsection{Precipitation}

Precipitation data sets used in this study are derived from three different products from the CloudSat CPR, namely 2B-GEOPROF, 2C-PRECIP-COLUMN, and 2CRAIN-PROFILE. All the estimates are limited to cloudy profiles by using 2B-GEOPROF cloud mask, which is set to greater than 20 (King et al., 2015). For the 2B-GEOPROF product (Marchand et al., 2008), the maximum radar reflectivity for each cloudy profile is used to define rain events and to estimate rain rate. More specifically, rain rate is obtained by employing the reflectivity-rainfall $(Z-R)$ relationship at cloud base ( $Z=25 R^{1.3}$ from Comstock et al., 2004), and a radar reflectivity threshold is used to distinguish between drizzling and non-drizzling clouds (Terai et al., 2012, 2015).

The empirical $Z-R$ relationship, however, does not account for multiple scattering by raindrops and attenuation due to both gases and hydrometeors, which poses major challenges for calculation of rain rate, especially surface rain rate (Lebsock and L'Ecuyer, 2011). To address those challenges, Haynes et al. (2009) introduced a full rainfall retrieval algorithm, which is the basis of the 2C-PRECIP-COLUMN product. The algorithm first makes use of path-integrated attenuation (PIA) derived from measurements of radar backscatter over the ocean surface in conjunction with surface wind speed and sea surface temperature. Surface rain rate is then estimated based on a simple algorithm using the PIA. For the 2C-PRECIP-COLUMN product, a rain event is identified by using rain likelihood mask. Here, we use the flag of "rain certain" to define a rain event, which means attenuationcorrected reflectivity near the surface is above $0 \mathrm{dBZ}$ (Haynes et al., 2009).

2C-PRECIP-COLUMN assumes a constant vertical rain profile in the precipitating column (Haynes et al., 2009), which may not be suitable for warm rain where vertical variation of the rain profile is significant (Lebsock and L'Ecuyer, 2011). To address this issue, CloudSat developed a third rain product, $2 \mathrm{C}$-RAIN-PROFILE, that utilizes the complete vertically resolved reflectivity profile observed by the CPR and incorporates a subcloud evaporation model. 2C-RAINPROFILE also uses MODIS cloud visible properties to constrain cloud water in its retrieval algorithm (Lebsock and L'Ecuyer, 2011). Note that the 2C-RAIN-PROFILE algorithm directly uses the precipitation occurrence flag from $2 \mathrm{C}$ PRECIP-COLUMN to define rain events. Thus, the probability of precipitation (POP) is the same for both rain products. Note that surface rain rates are only retrieved for those pixels that identified as rain certain in the 2C-RAINPROFILE product (Lebsock and L'Ecuyer, 2011). Overall, three rain rate data sets in this study are significantly different: rain rate directly estimated from 2B-GEOPROF represents the maximum rainfall rate, precipitation from $2 \mathrm{C}$ -
PRECIP-COLUMN is the column-mean rainfall rate, and rain rate from $2 \mathrm{C}$-RAIN-PROFILE stands for surface rainfall rate.

\subsection{Meteorological data sets}

Aerosol-cloud-precipitation interactions and precipitation susceptibility have been shown to depend on cloud regimes (L'Ecuyer et al., 2009). Following Klein and Hartmann (1993), we use the lower-tropospheric static stability (LTSS), which is defined as the difference in potential temperature between $700 \mathrm{hPa}$ and the surface, to separate different atmosphere thermodynamic regimes. In this study, unstable and stable environments are defined as LTSS less than $13.5 \mathrm{~K}$ and LTSS larger than $18 \mathrm{~K}$, respectively. Pixels where LTSS is between 13.5 and $18 \mathrm{~K}$ are defined as the midstable environment (Wang et al., 2012). The European Centre for MediumRange Weather Forecasts auxiliary (ECMWF-AUX) product, as an ancillary CloudSat product that contains temperature and pressure within each CPR bin, is used to calculate LTSS.

\subsection{Precipitation susceptibility calculation}

Following previous studies (Feingold and Siebert, 2009; Sorooshian et al., 2009; Wang et al., 2012; Terai et al., 2012, 2015), precipitation susceptibility is generally defined as

$S_{\mathrm{X} \_\mathrm{Y}}=-\frac{\mathrm{d} \ln X}{\mathrm{~d} \ln Y}$,

where $X$ can be substituted by POP (precipitation frequency), $I$ (precipitation intensity), or $R(R=\mathrm{POP} \times I$, precipitation rate), and $Y$ indicates AI or CDNC. Consequently, six different precipitation susceptibilities can be obtained from the observations described above. To constrain the cloud macrophysical environment, all samples are sorted according to their LWP values first and then divided into 10 LWP bins. The ratio of the number of pixels in each bin to the total pixels ranges from 5 to $14 \%$. For each LWP bin, samples are sorted by $\mathrm{AI}$ or CDNC, and $10 \mathrm{AI} / \mathrm{CDNC}$ bins are equally divided to calculate $\mathrm{POP}$, mean $I, R, \mathrm{AI}$, and CDNC within each AI/CDNC bin. Finally, the values of $S_{X_{-}}$ are derived by linear regression in log-log space.

\section{Results}

\section{1 $S_{\mathrm{X} \_ \text {AI }}$ vs. $S_{\mathrm{X} \_ \text {CDNC }}$}

$S_{\mathrm{X} \_\mathrm{AI}}$ and $S_{\mathrm{X} \_\mathrm{CDNC}}$ as a function of LWP are shown in Fig. 1. Here, LWP from MODIS and rain data from 2B-GEOPROF with a rain threshold of $-15 \mathrm{dBZ}$ are used to better compare with other satellite studies (Terai et al., 2015; Michibata et al., 2016). Here, AI is estimated by using the MYD04 data set, and detailed comparison among different aerosol products will be made in Sect. 3.2. 

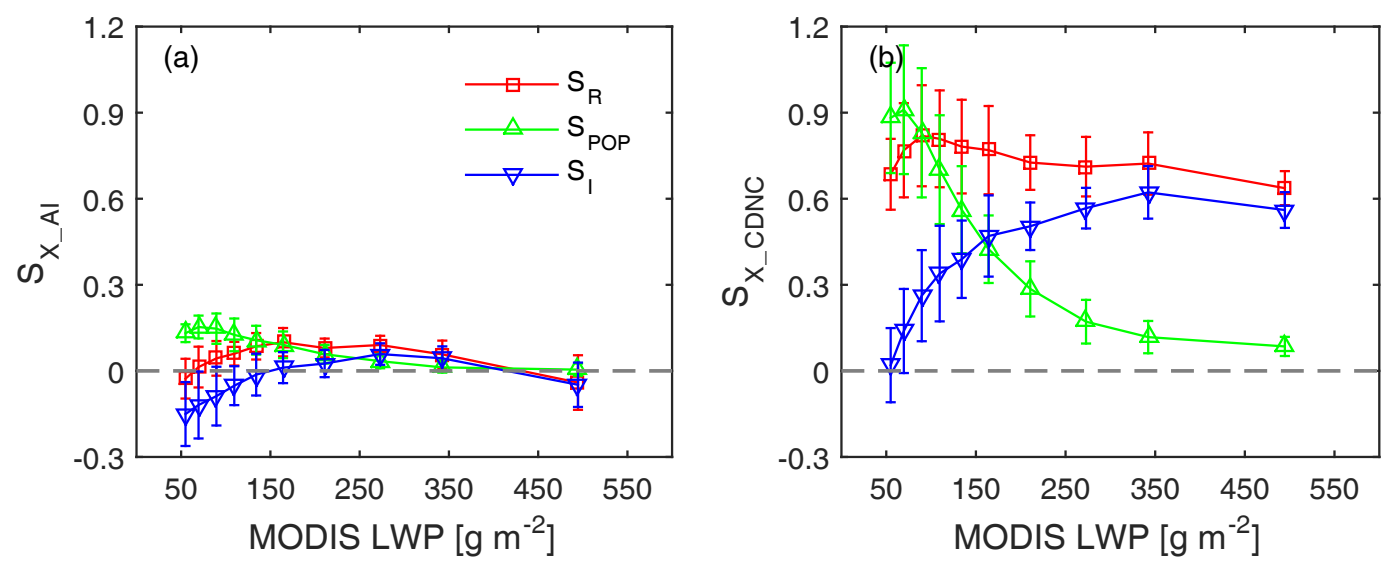

Figure 1. $S_{\mathrm{POP}}, S_{\mathrm{I}}$, and $S_{\mathrm{R}}$ as a function of MODIS LWP with (a) AI and (b) CDNC. Red squares, green upward triangles, and blue downward triangles stand for $S_{\mathrm{R}}, S_{\mathrm{POP}}$, and $S_{\mathrm{I}}$, respectively. Error bars are based on $95 \%$ confidence intervals for the susceptibility estimates. AI is derived from MYD04/MODIS and CDNC is estimated from MYD06/MODIS. Intensity and probability of precipitation are based on the 2B-GEOPROF product with a $-15 \mathrm{dBZ}$ threshold. The total amounts of data samples for the left panel and right panel are about 2.1 and 3.1 million.

Consistent with previous studies, $S_{\mathrm{X} \_\mathrm{AI}}$ are generally much smaller than $S_{X_{-} C D N C}$ as shown in Fig. 1. $S_{\text {POP_AI }}$ from Wang et al. (2012) is less than 0.2 over all LWP bins, while Terai et al. (2015) showed that $S_{\text {POP_CDNC decreases }}$ with increasing LWP, ranging from 1 to 0 , and $S_{R_{-} C D N C}$ is maintained at around 0.5 . Figure $1 \mathrm{~b}$ further shows $S_{I_{-} C D N C}$ monotonically increases with LWP, followed by a slight de-

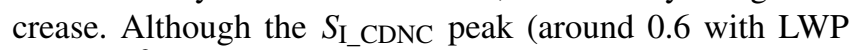
$350 \mathrm{~g} \mathrm{~m}^{-2}$ ) is not significant in Fig. 1b, $S_{\text {I_CDNC }}$ would decrease distinctly after the peak if the upper bound of LWP and the number of LWP bins both increase (not shown). This turning point may correspond to the conversion process shifting from the autoconversion to accretion regime (Michibata et al., 2016).

To account for discrepancy between $S_{\mathrm{X} \_ \text {AI }}$ and $S_{\mathrm{X} \_ \text {CDNC, }}$ we use the condition probability method (Gryspeerdt et al., 2016) to explore relationships between AI and CDNC. As Fig. 2a shows, the majority of CDNC values concentrate on the intervals between 20 to $100 \mathrm{~cm}^{-3}$, representing an upward tendency with increasing AI over global oceans. The similar feature of CDNC with AI is also shown in different LTSS conditions (Fig. 2b-d). Note that fluctuation of the curve at high AI results from the small number of effective pixels, especially in the unstable condition.

To formally account for the relationship between CDNC and AI, $S_{\mathrm{X} \_\mathrm{AI}}$ can be decomposed into two parts:

$$
\begin{aligned}
S_{\mathrm{X} \_\mathrm{AI}} & =-\frac{\mathrm{d} \ln X}{\mathrm{~d} \ln \mathrm{AI}}=-\frac{\mathrm{d} \ln X}{\mathrm{~d} \ln \mathrm{CDNC}} \frac{\mathrm{d} \ln \mathrm{CDNC}}{\mathrm{d} \ln \mathrm{AI}} \\
& =S_{\mathrm{X} \_\mathrm{CDNC}} \frac{\mathrm{d} \ln \mathrm{CDNC}}{\mathrm{d} \ln \mathrm{AI}},
\end{aligned}
$$

where $\mathrm{d} \ln \mathrm{CDNC} / \mathrm{d} \ln \mathrm{AI}$ is the link between $S_{\mathrm{X} \_\mathrm{AI}}$ and $S_{\mathrm{X}_{-} \text {CDNC. }} S_{\mathrm{X}_{-} \mathrm{AI}}$ is expected to be smaller than $S_{\mathrm{X}_{-} \mathrm{CDNC}}$ if $\mathrm{d} \ln \mathrm{CDNC} / \mathrm{d} \ln \mathrm{AI}$ is smaller than 1 . Figure 3 shows $\mathrm{d} \ln \mathrm{CDNC} / \mathrm{d} \ln \mathrm{AI}$ over global oceans, which is calculated by $\log -\log$ linear regressions in each MODIS LWP bin. $\mathrm{d} \ln \mathrm{CDNC} / \mathrm{d} \ln \mathrm{AI}$ is smaller than 0.4 , which explains why $S_{\mathrm{X} \_ \text {AI }}$ is generally smaller than $S_{\mathrm{X} \_ \text {CDNC. Table }} 3$ further shows the LWP-weighted mean of d $\ln C D N C / d \ln$ AI, $S_{\text {X_AI }}$, and $S_{\mathrm{X} \_\mathrm{CDNC}}$ over global oceans. Our results are consistent with the previous satellite observations. For instance, $S_{\text {POP_AI }}$ is equal to 0.11 in our results obtained from AMSRE LWP, close to the value of 0.12 in Wang et al. (2012), and our $S_{\mathrm{R}}$ CDNC derived from MODIS LWP is 0.74 , similar to that (0.6) in Terai et al. (2015). Since the global mean $\mathrm{d} \ln \mathrm{CDNC} / \mathrm{d} \ln \mathrm{AI}$ is about 0.3 , we would expect $S_{\mathrm{X} \_\mathrm{AI}}$ to be about one-third of $S_{\mathrm{X} \_\mathrm{CDNC}}$, according to Eq. (7). Table 3 shows that this relationship is generally true for $S_{\mathrm{POP}}$ but less so for $S_{\mathrm{I}}$, especially for $S_{\mathrm{I}}$ calculated based on MODIS LWP.

Table 3 further demonstrates that $S_{\mathrm{R}} \approx S_{\mathrm{I}}+S_{\mathrm{POP}}$ is generally true for different LWP products and over different stability regimes, consistent with Terai et al. (2015).

\section{2 $S_{\mathrm{X} \_\mathrm{AI}}$ from different aerosol products}

Now, we explore how precipitation susceptibility estimates might be different from different aerosol products (i.e., MYD04, MYD08, and CAL_LID_L2_05kmALay). As shown in Fig. 4, despite differences in their horizontal resolutions $\left(10 \mathrm{~km}\right.$ vs. $\left.1^{\circ}\right), S_{\mathrm{X} \_A I}$ calculated from MYD04 and MYD08 agrees well (Fig. 4a and b), which may result from the fact that aerosol layers are likely homogeneous over relatively large spatial scales less than $200 \mathrm{~km}$ (Anderson et al., 2003), especially over global oceans. In addition, McComiskey and Feingold (2012) found that the statistics (i.e., min, max, and variance) of AOD are constant between MYD04 and MYD08 products over the northeast Pacific Ocean for a given day. Although not shown here, the proba- 
(a)

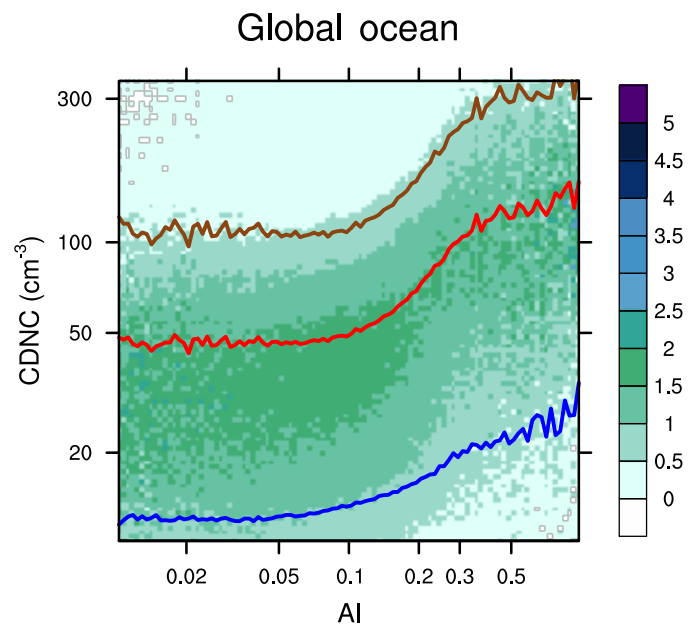

(c)

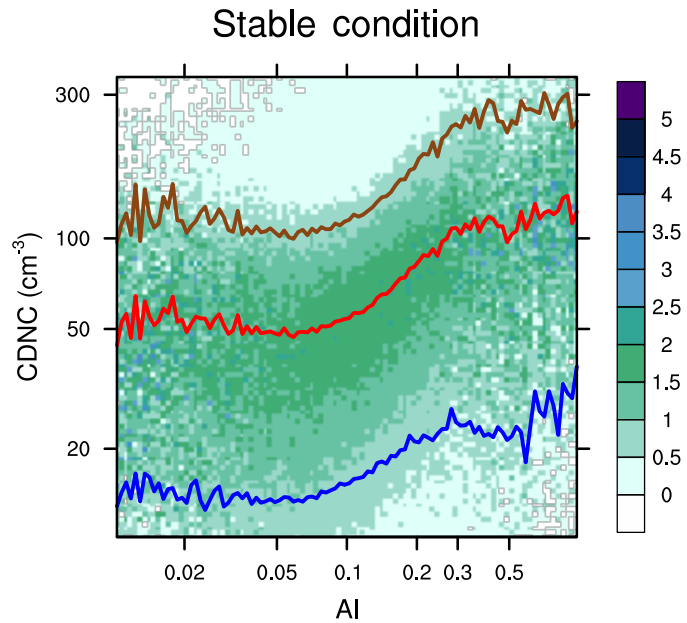

(b)

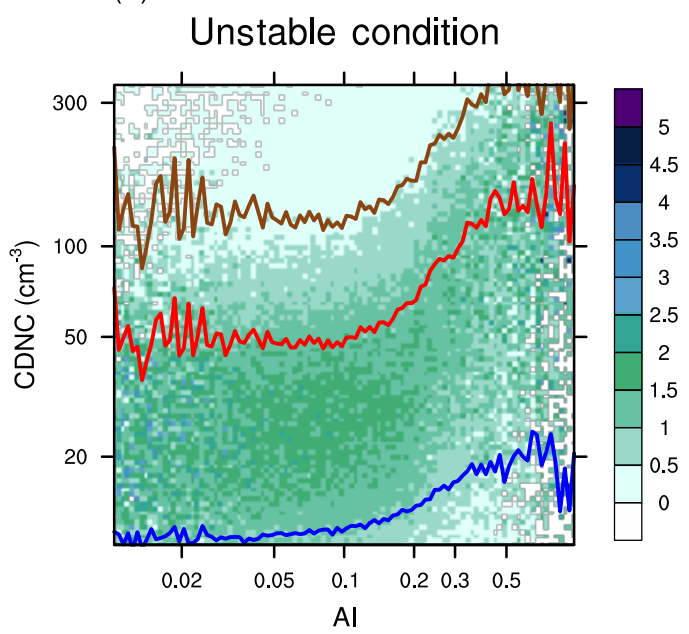

(d)

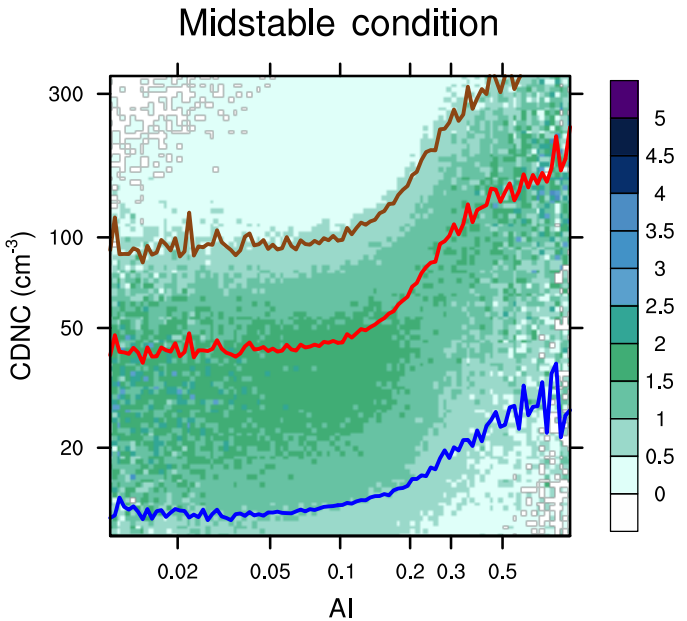

Figure 2. The probability of CDNC under given AI over the (a) global ocean, (b) unstable, (c) stable, and (d) midstable conditions. In each figure, the red line represents change in average CDNC with AI, and the lower and upper lines stand for mean CDNC for the 25th percentile and 75th percentile of samples. AI and CDNC are estimated from MYD04 and MYD06, respectively.

Table 3. The LWP weighted-mean values of precipitation susceptibility $S_{X_{-}}$Y and d ln CDNC/dln AI over global oceans under different stability regimes. The statistics are based on the $2 \mathrm{~B}-\mathrm{GEOPROF} / \mathrm{CPR}$ product using the cloud base $Z-R$ relationship and a $-15 \mathrm{dBZ}$ threshold.

\begin{tabular}{llrrrrrrrr}
\hline & $S_{\text {R_AI }}$ & $S_{\text {I_AI }}$ & $S_{\text {POP_AI }}$ & $S_{\text {R_CDNC }}$ & $S_{\text {I_CDNC }}$ & $S_{\text {POP_CDNC }}$ & d ln CDNC/dln AI \\
\hline \multirow{2}{*}{ MODIS LWP } & Global & 0.05 & -0.02 & 0.08 & 0.74 & 0.47 & 0.44 & 0.28 \\
& Unstable & -0.04 & -0.09 & 0.04 & 0.52 & 0.30 & 0.26 & 0.22 \\
& Stable & 0.22 & 0.13 & 0.12 & 0.84 & 0.48 & 0.60 & 0.30 \\
& Midstable & 0.01 & -0.05 & 0.07 & 0.66 & 0.39 & 0.35 & 0.29 \\
\hline \multirow{2}{*}{ AMSR-E LWP } & Global & 0.17 & 0.07 & 0.11 & 0.47 & 0.16 & 0.37 & 0.32 \\
& Unstable & 0.14 & 0.06 & 0.08 & 0.21 & 0.04 & 0.18 & 0.25 \\
& Stable & 0.29 & 0.17 & 0.15 & 0.67 & 0.23 & 0.55 & 0.33 \\
& Midstable & 0.13 & 0.04 & 0.10 & 0.40 & 0.13 & 0.29 & 0.34 \\
\hline
\end{tabular}

bility distributions of AI derived from MYD04 and MYD08 products are qualitatively similar over global oceans. In comparison with the results based on MODIS retrievals, $S_{\mathrm{X} \_\mathrm{AI}}$ obtained from CALIOP (Fig. 4c) is smaller and relatively flat across all LWP bins. Further testing shows that $S_{\mathrm{X} \_ \text {AI }}$ using CALIOP AOD but MYD04 AE agrees better with that based 


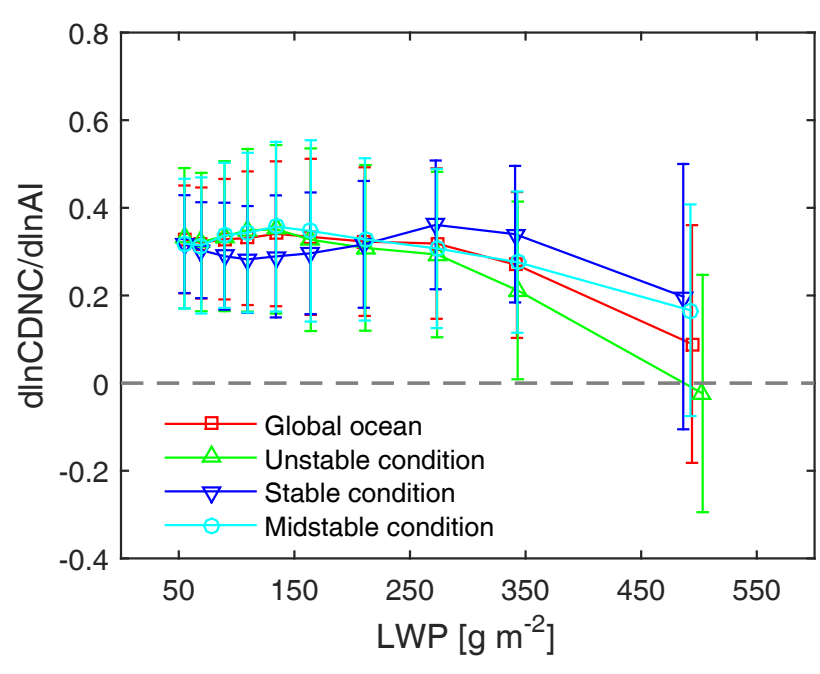

Figure 3. $d \ln C D N C / d \ln A I$ obtained by linear regression of $\ln$ CDNC and $\ln$ AI under MODIS LWP bins. Red lines denote the global ocean. Green, blue, and cyan stand for unstable, stable, and midstable conditions, respectively. AI and CDNC are estimated from MYD04 and MYD06.

on MODIS aerosol products (Fig. 4d). This suggests that differences in AE estimates from MODIS and CALIOP largely explain the discrepancy between two aerosol products. Previous studies indicate that MODIS and CALIOP AOD are poorly correlated (e.g., Costantino and Bréon, 2010; Kim et al., 2013; Kittaka et al., 2011; Ma et al., 2013). Our results suggest that differences in AOD retrievals can lead to differences in AE estimates and further affect $\mathrm{AI}$ and precipitation susceptibly estimates. Given that AI from MODIS has been widely used in previous studies for examining aerosolcloud-precipitation interactions, for the rest of the paper, AI from MYD04 is used, unless otherwise stated.

\section{3 $S_{X_{-} Y}$ from different LWP data sets}

Figure 5 shows the behavior of $S_{\mathrm{POP}}$ and $S_{\mathrm{I}}$ based on different LWP data sets (i.e., AMSR-E and MODIS LWP). Estimates of rain rate and rain events are based on 2B-GEOPROF with a $-15 \mathrm{dBZ}$ threshold as mentioned in Sect. 2.1.3. Here, we focus on characteristics of $S_{\mathrm{POP}}$ and $S_{\mathrm{I}}$ since $S_{\mathrm{R}} \approx S_{\mathrm{I}}+S_{\mathrm{POP}}$ as mentioned in Sect. 3.1. As shown in Fig. 5a, $S_{\text {POP_CDNC }}$ based on MODIS LWP is similar to that calculated based on AMSR-E LWP. This consistency is also found for $S_{\text {POP_AI }}$. In contrast, $S_{\text {I_CDNC }}$ and $S_{\text {I_AI }}$ calculated based on two LWP products are quite different (Fig. 5b). $S_{I_{-} \text {CDNC }}$ based on MODIS LWP is significantly larger than that based on AMSR-E LWP over all LWP bins (see upward triangles in Fig. 5b), while $S_{\text {I_AI }}$ from two LWP products shows an opposite pattern: $S_{\text {I_AI }}$ based on MODIS LWP is lower than that based on AMSR-E LWP (see downward triangles in Fig. 5b). These features of discrepancies in $S_{I}$ between MODIS and AMSR-E LWP are still applicable to $S_{\mathrm{POP}}$, though the mag- nitude is much smaller and is not statistically significant (Fig. 5a).

Figure $5 \mathrm{~b}$ shows that LWP value where $S_{\text {I_CDNC }}$ peaks based on MODIS LWP is larger than that based on AMSR-E LWP. Large eddy simulation analysis by Duong et al. (2011) showed a similar shift in LWP with changing spatial resolutions, which is attributed to reduction in mean LWP at coarser resolutions. However, Fig. 6 shows that there is no systematic shift in the frequency distribution of LWP between two LWP products, regardless of precipitation or nonprecipitation samples.

To better understand the discrepancy in precipitation susceptibility estimates from two LWP products in Fig. 5, we plot POP and intensity as a function of CDNC/AI in log space for each LWP bin obtained from MODIS and AMSRE. Figure $7 \mathrm{a}-\mathrm{d}$ show that the relationships between POP and CDNC (AI) from MODIS LWP are similar to those from AMSR-E LWP. In contrast, intensity vs. CDNC (AI) between two LWP products shows large differences (Fig. 7eh). Figure 7f shows that intensity is positively correlated with CDNC at low CDNC for high AMSR-E LWP bins, which helps to explain why $S_{\text {I_CDNC }}$ from AMSR-E LWP is smaller than that from MODIS, especially at high LWP bins (Fig. 5b).

Combining Eqs. (4) and (5), CDNC from MODIS can be reformulated as a function of LWP and $r_{\text {eff }}$ :

$\mathrm{CDNC}=\alpha\left(a \rho_{\mathrm{w}}\right)^{-0.5} \mathrm{LWP}^{0.5} r_{\mathrm{eff}}^{-3}$,

where $\alpha, a$, and $\rho_{\mathrm{w}}$ are all constant. Accordingly, $r_{\mathrm{eff}}$ decreases with increasing CDNC for any given MODIS LWP bin, and larger CDNC leads to smaller $r_{\text {eff }}$, which further results in reduction in precipitation efficiency, as shown in Fig. 7e. The $\mathrm{CDNC}-\mathrm{r}_{\text {eff }}$ relationship still holds when data are binned by AMSR-E LWP and $r_{\text {eff }}$ decreases with increasing CDNC even at larger LWP AMSR-E LWP bins (Fig. 8a). We would then expect that rain intensity still decreases with increasing CDNC for the AMSR-E LWP at low CDNC. So then what might lead to increases in precipitation intensity with increasing $\mathrm{CDNC}$ at low $\mathrm{CDNC}$ when data are binned according to constant AMSR-E LWP (Fig. 7f)? Our analysis suggests that this might come from the discrepancies in two LWP products under low CDNC. Figure $8 \mathrm{~b}$ shows that, under constant AMSR-E LWP, MODIS LWP significantly varies with CDNC (Fig. 8b). In particular, MODIS LWP rapidly increases with $\mathrm{CDNC}$ at low $\mathrm{CDNC}$, which might explain why rain intensity increases with increasing CDNC at low CDNC under constant AMSR-E LWP, which further leads to much

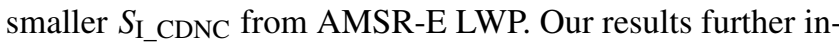
dicate that rain intensity retrieval from CloudSat might be more consistent with LWP retrieval from MODIS than that from AMSR-E, as under constant AMSR-E LWP, rain intensity increases with increasing MODIS LWP at low CDNC (Figs. 7f and 8b).

It is interesting to note that, for rainy pixels, the difference in LWP between MODIS and AMSR-E varies with 

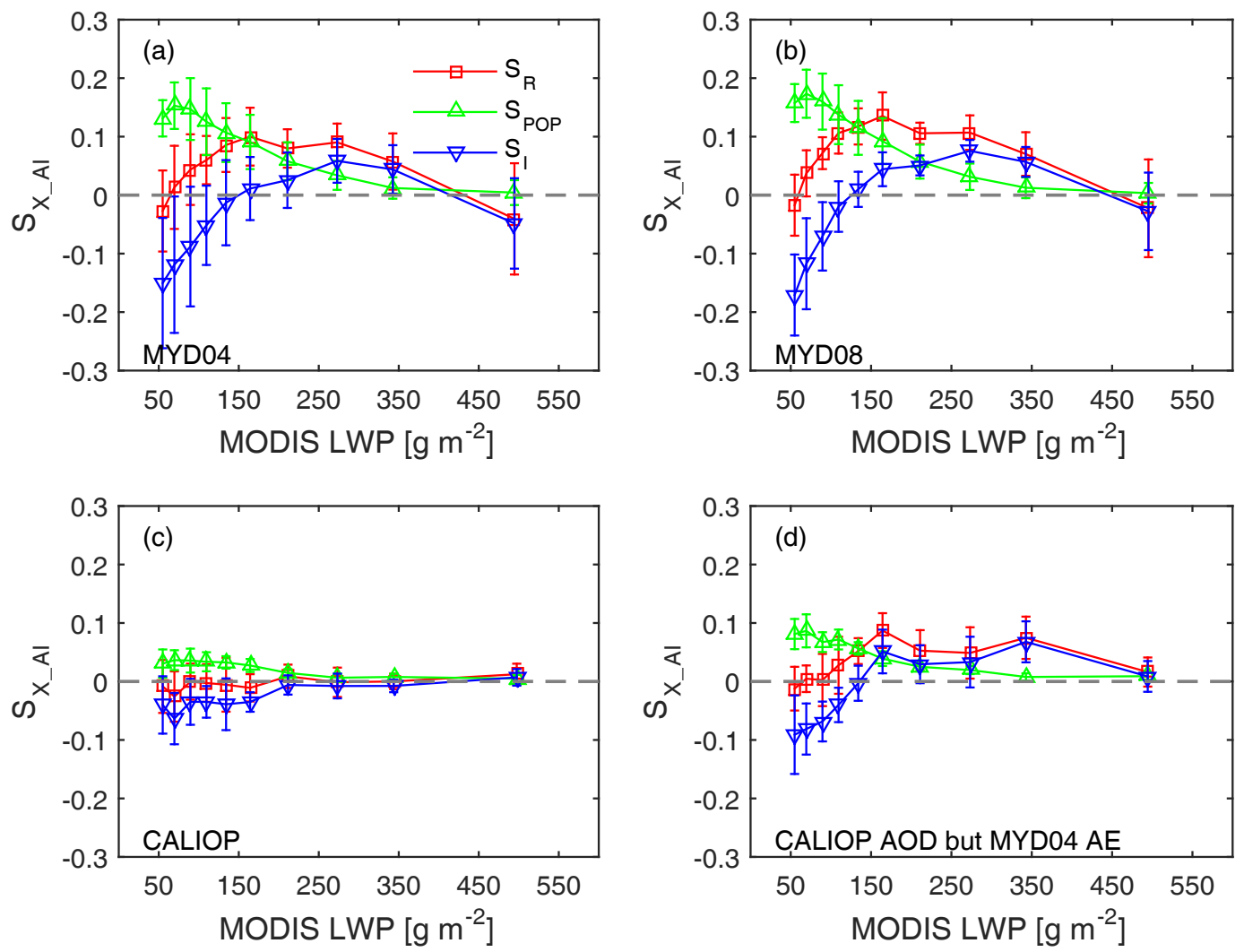

Figure 4. Susceptibilities $\left(S_{\mathrm{X} \_A I}\right)$ as a function of MODIS LWP. The rain product used is the same as that in Fig. 1. AI is derived from (a) MYD04/MODIS, (b) MYD08/MODIS, and (c) CAL_LID_L2_05kmALay/CALIOP products. Panel (d) is the same as (c) but using MYD04 AE.
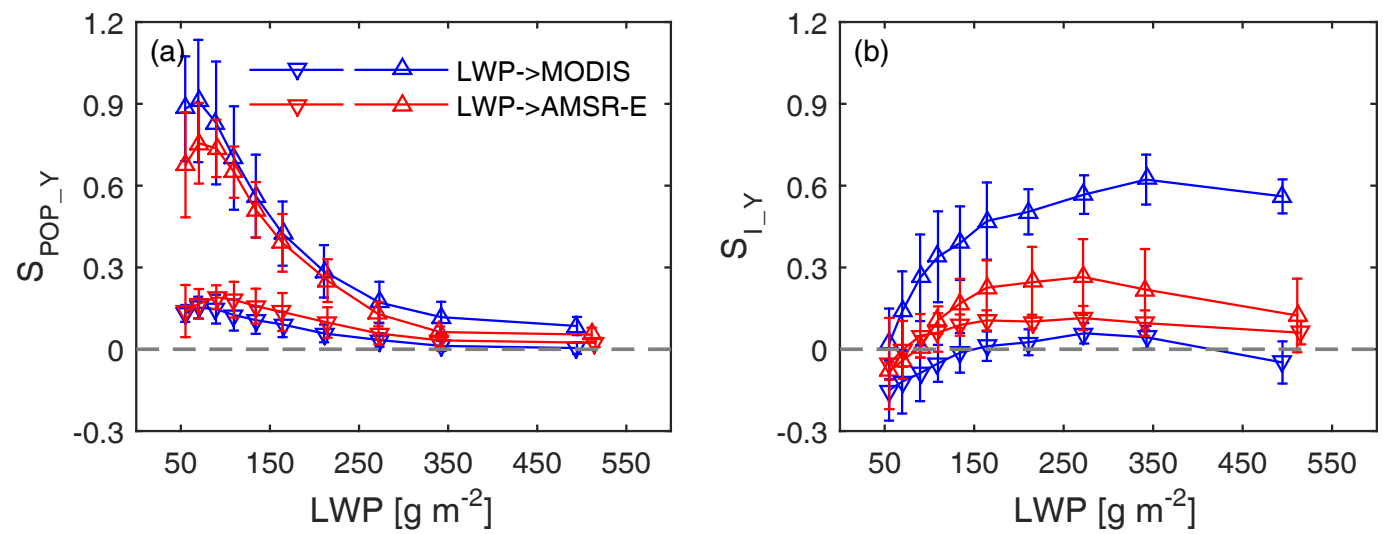

Figure 5. (a) $S_{\text {POP_Y }}$ and (b) $S_{\text {I_Y }}$ as a function of LWP. The subscript Y denotes different aerosol proxies corresponding to AI (downward triangles) and CDNC (upward triangles). Blue (red) represents LWP derived from MODIS (AMSR-E). The rain product used is the same as that in Fig. 1. AI and CDNC are estimated from MYD04 and MYD06, respectively.

MODIS CDNC. Under constant AMSR-E LWP (larger than $200 \mathrm{~g} \mathrm{~m}^{-2}$ ), MODIS LWP dramatically increases with increasing CDNC at lower CDNC $\left(<\sim 25 \mathrm{~cm}^{-3}\right)$. These features are also applicable to non-rainy samples (not shown). Further studies are needed to understand the aforementioned discrepancy.

\section{4 $S_{X_{-} Y}$ from different rainfall definitions}

Given that rainy samples may be dominated by different precipitation process (e.g., autoconversion vs. accretion processes) with increasing threshold for defining a rainfall event (Jung et al., 2016), precipitation susceptibility may 


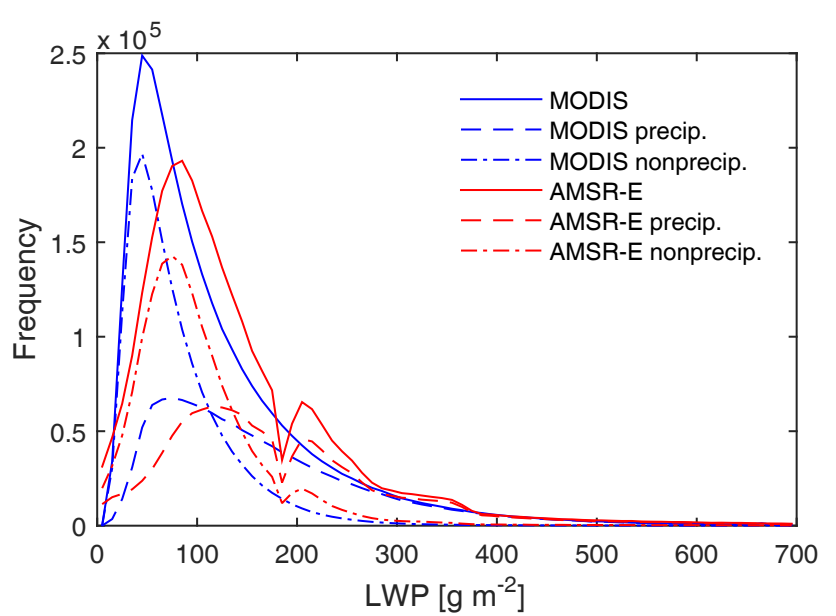

Figure 6. Distribution of frequency of LWP derived from MODIS and AMSR-E under different scenarios, namely, all samples, nonprecipitation and only-precipitation samples.

be changed when we apply different rainfall thresholds. To examine this, we plot $S_{\mathrm{POP}}$ and $S_{\mathrm{I}}$ under different thresholds (i.e., -15 and $0 \mathrm{dBZ}$ of maximum radar reflectivity) used to define a rain event based on 2B-GEOPROF products. These thresholds of -15 and $0 \mathrm{dBZ}$ correspond to approximate precipitation rates of 0.14 and $2 \mathrm{~mm} \mathrm{~d}^{-1}$, respectively (Comstock et al., 2004). Hence, precipitation susceptibilities under these two thresholds can be referred to as drizzle $(>-15 \mathrm{dBZ})$ and rain $(>0 \mathrm{dBZ})$ susceptibilities. As Fig. 9 indicates, the difference in $S_{\mathrm{X}_{-} \mathrm{AI}}$ between drizzle and rain is, at first glance, less evident compared to $S_{\mathrm{X}_{-} \mathrm{CDNC}}$. This can be partly attributed to the low values of $S_{\mathrm{X} \_ \text {AI }}$ themselves. Relative differences in $S_{\mathrm{X} \_\mathrm{AI}}$ are even larger than those of $S_{\mathrm{X} \_ \text {CDNC }}$ at low AMSR-E LWP (not shown). Figure 9a and c show that rain $S_{\text {POP_AI }}$ is higher than that of drizzle over most LWP bins, which is consistent with results from Wang et al. (2012).

The rainfall definition significantly impacts $S_{\text {POP_CDNC }}$

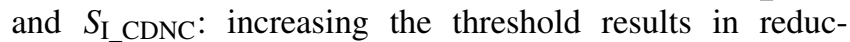
tion of $S_{I_{-} C D N C}$ over all LWP and, by contrast, leads to a distinct increase in $S_{\mathrm{POP}}$ CDNC, especially at moderate LWP (see Fig. 9). These overall changes in $S_{\text {I_CDNC }}$ and $S_{\text {POP_CDNC }}$ after increasing the threshold are consistent with Terai et al. (2015). The observational results from Mann et al. (2014) have also shown an evident increase in $S_{\mathrm{POP}}$ with respect to $N_{\mathrm{CCN}}$ at high LWP with increasing thresholds. The systematic increase in $S_{\text {POP_CDNC may result from }}$ a larger proportion of non-drizzling samples with an increasing threshold. The reduction of $S_{\text {I_CDNC }}$ is in agreement with previous studies (Duong et al., 2011; Jung et al., 2016). Although not shown here, for a fixed threshold, there is no significant discrepancy between the results of $S_{I_{Z} C D N C}$ and $S_{\mathrm{R}}$ CDNC based on different $Z-R$ relationships $\left(Z=25 R^{1.3}\right.$ and $Z=302 R^{0.9}$ are used both from Comstock et al., 2004, which aim at cloud base and surface rain rate, respectively), which is consistent with the result from Terai et al. (2012).

Overall, our results show that $S_{\mathrm{POP}}$ and $S_{\mathrm{I}}$ are both sensitive to the rainfall definition and that $S_{\mathrm{POP}}$ is greater for rain while $S_{\mathrm{I}}$ is greater for drizzle. Our results further imply that the onset of drizzle is not as readily suppressed in warm clouds as rainfall (i.e., $S_{\mathrm{POP}}$ is greater for rain than for drizzle). By contrast, $S_{\mathrm{R}}$ is not affected by the rainfall definition since the mean rain rate $R$ for a given LWP/CDNC or LWP/AI bin is calculated based on both rainy and nonrainy clouds and does not depend on rainfall thresholds (not shown).

While the response of precipitation susceptibility to change in threshold shows the same pattern between MODIS and AMSR-E LWP (Fig. 9), the extent to which susceptibility changes with an increasing threshold is quite different between these LWP products. Overall, sensitivity of $S_{\mathrm{X} \_\mathrm{CDNC}}$ to different thresholds using MODIS LWP is larger than that based on AMSR-E LWP; this pattern is opposite for $S_{\mathrm{X} \_\mathrm{AI}}$. It is interesting to note that while the difference in $S_{\mathrm{POP}}$ between MODIS and AMSR-E LWP is small with the $-15 \mathrm{dBZ}$ threshold (Figs. 5, 9a and c), the difference is relatively larger for the $0 \mathrm{dBZ}$ threshold (Fig. 9a and c), especially at larger LWP bins.

\section{5 $S_{X_{-} \_}$from different precipitation data sets}

The diverse rain data sets allow us to explore differences in precipitation susceptibility estimates from different rain products. In Fig. 10, we illustrate $S_{\mathrm{POP}}$ and $S_{\mathrm{I}}$ for different rain data sets, namely, 2B-GEOPROF, 2C-PRECIPCOLUMN, and 2C-RAIN-PROFILE (Marchand et al., 2008; Haynes et al., 2009; Lebsock and L'Ecuyer, 2011) products. Here, we use LWP derived from MODIS and use the rain certain flag for rain definition reported in the latter two rain products. Since the precipitation flags used in these two rain products are identical (Lebsock and L'Ecuyer, 2011), only $S_{\text {POP }}$ based on 2C-PRECIP-COLUMN is plotted in Fig. 10. For 2B-GEOPROF, the threshold of $0 \mathrm{dBZ}$ radar reflectivity is used to define a rain event and rain rate is estimated by using $Z=25 R^{1.3}$ suggested by Comstock et al. (2004). Note that using the rain certain flag or a threshold of $0 \mathrm{dBZ}$ to identify rain events for those rain products would result in a reduction of rain events across all LWP bins, especially at low LWP bins; therefore, we expand bounds of low LWP bins to include enough rain samples at low LWP bins.

$S_{\text {POP }}$ exhibits a similar dependence on LWP among these three rain products, but $S_{\mathrm{POP}}$ based on 2B-GEOPROF is systematically larger than that based on 2C-PRECIP-COLUMN (this is also true for $S_{\mathrm{I}}$ ). It is unclear what might lead to higher $S_{\text {POP }}$ and $S_{\text {I }}$ from 2B-GEOPROF. The vertical structure of clouds may play a role here, as the maximum radar reflectivity is used from 2B-GEOPROF and surface rain rates are used from the other products. 

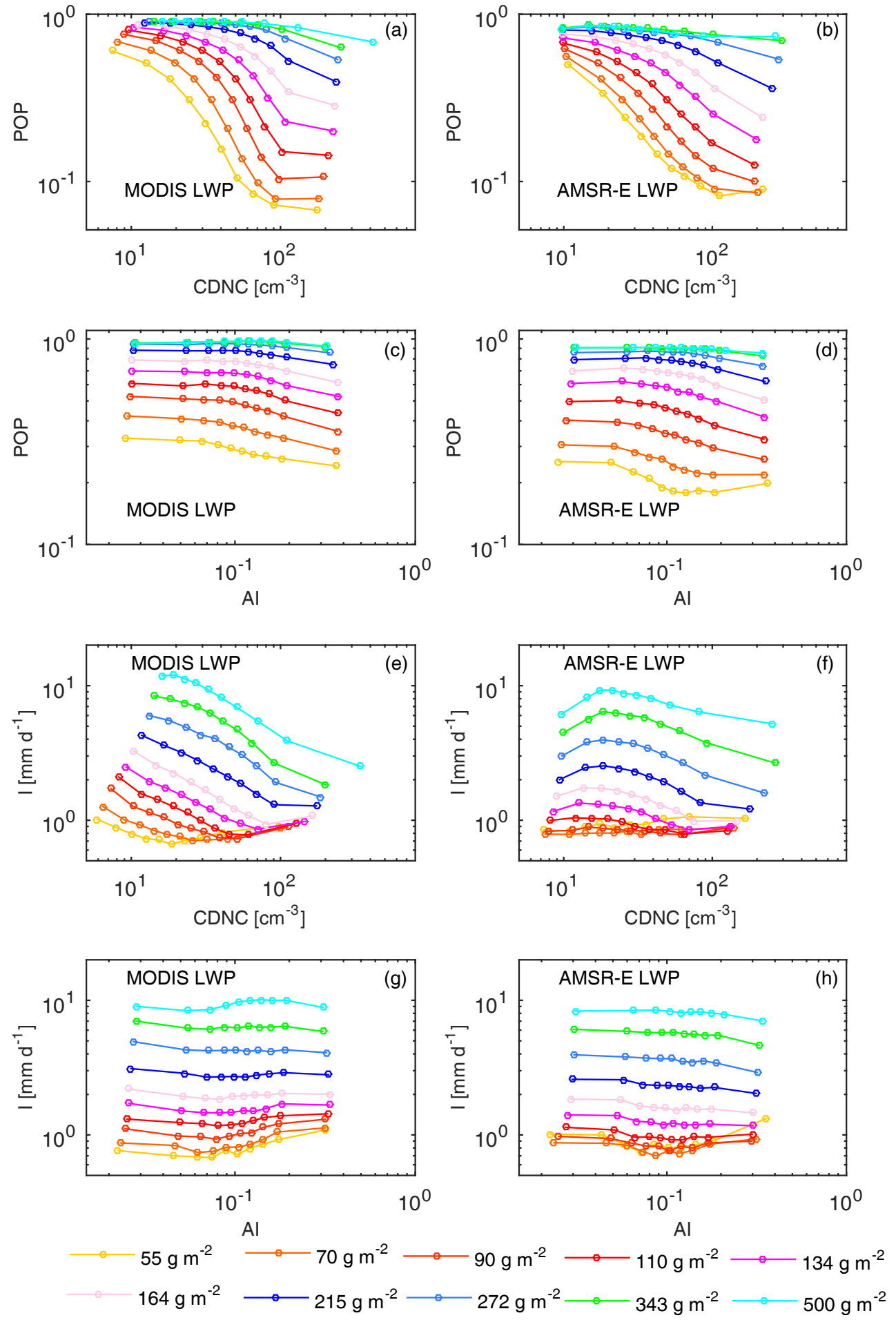

Figure 7. POP and I as a function of CDNC (AI) for each LWP bin obtained from (a, $\mathbf{c}, \mathbf{e}, \mathbf{g})$ MODIS and (b, d, f, h) AMSR-E. The data used here are the same as those in Fig. 5.

The most significant discrepancy occurs in $S_{I_{-} \text {CDNC }}$ and $S_{\text {I_AI }}$ (see Fig. 10b). Figure $10 \mathrm{~b}$ shows that $S_{\text {I_CDNC }}$ and $S_{\text {I_AI }}$ are both near zero for LWP $<400 \mathrm{~g} \mathrm{~m}^{-2}$, which may be attributed to high thresholds used among the three rain prod- ucts. This indicates that precipitation intensity with a high threshold is insensitive to CDNC and AI at moderate LWP. This result is consistent with Terai et al. (2015), who suggested that heavy drizzle intensity is insensitive to CDNC. As 

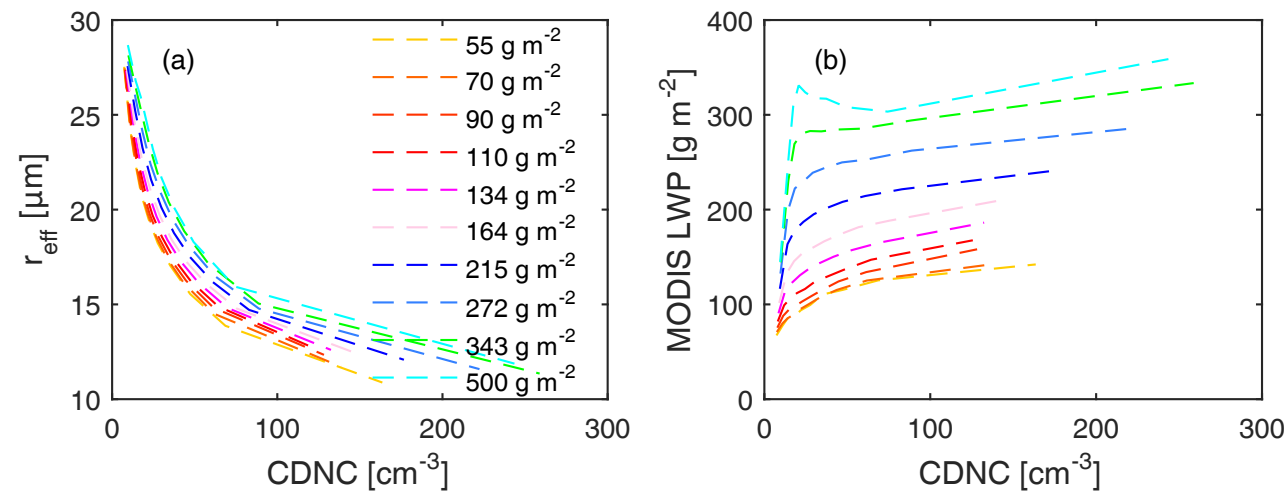

Figure 8. (a) $r_{\text {eff }}$ and (b) MODIS LWP as a function of CDNC for each AMSR-E LWP bin. Only rainy samples defined by a -15 dBZ threshold are used in here. Different color lines represent different AMSR-E bins corresponding to Fig. $7 \mathrm{f}$.
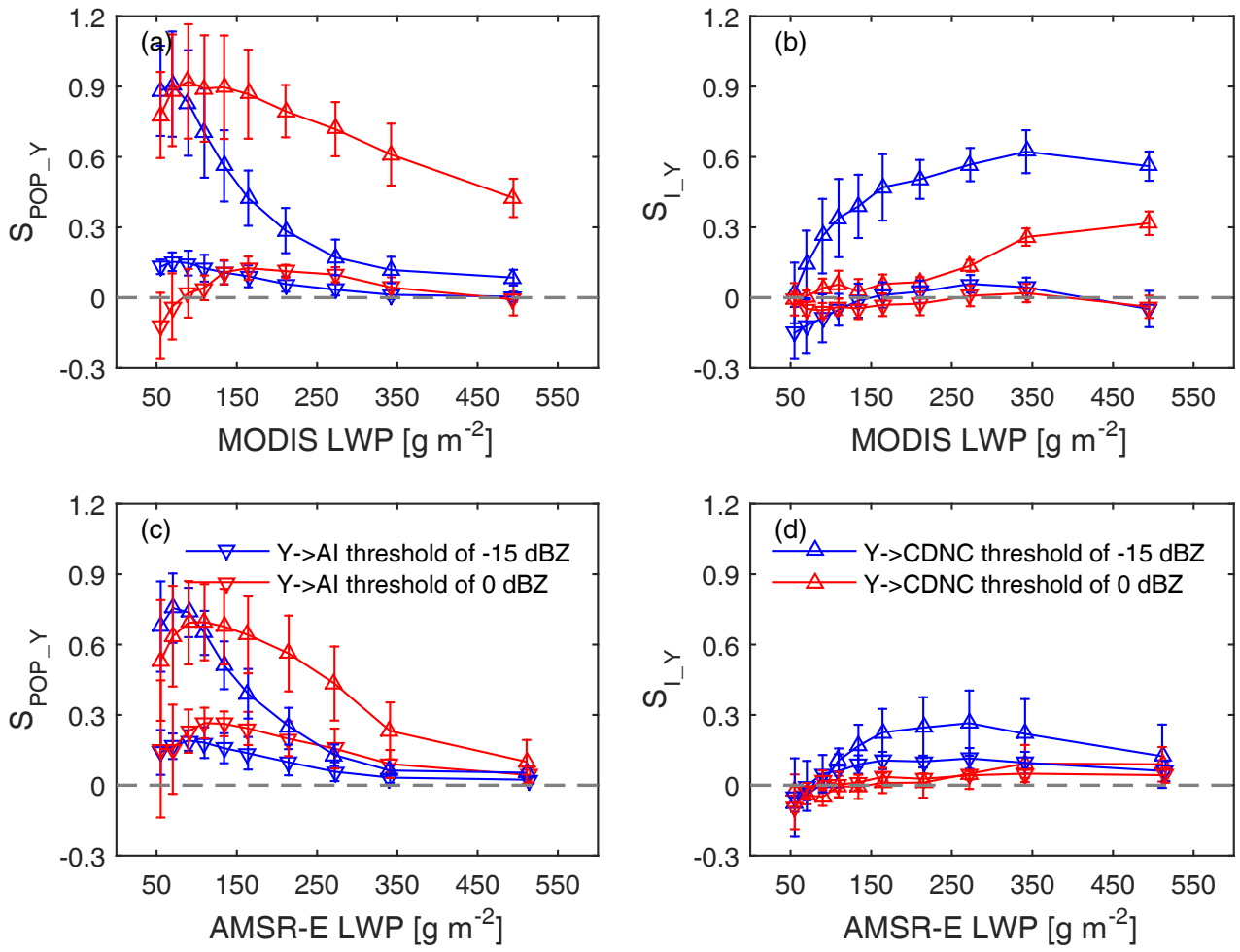

Figure 9. (a, c) $S_{\text {POP_Y }}$ and (b, d) $S_{\text {I_Y }}$ as a function of LWP. The subscript Y denotes different aerosol proxies corresponding to AI (downward triangles) and CDNC (upward triangles). The 2B-GEOPROF product is used here. Blue and red symbols represent $-15 \mathrm{dBZ}$ and $0 \mathrm{dBZ}$ thresholds, respectively. The top and bottom panels stand for MODIS and AMSR-E LWP, respectively.

Fig. 10b shows, SI_CDNC based on the 2C-RAIN-PROFILE product (red squares in Fig. 10b) with subcloud evaporation model incorporated is higher than that based on the 2C-PRECIP-COLUMN product (blue squares in Fig. 10b) at high LWP (above $300 \mathrm{~g} \mathrm{~m}^{-2}$ ). Hill et al. (2015) showed that, when considering rain evaporation, $S_{\text {I CDNC }}$ based on surface rain rate is larger than that based on cloud base and column maximum rain rate at $\mathrm{LWP}>400 \mathrm{~g} \mathrm{~m}^{-2}$. However, their difference is more obvious than our results, which may result from the threshold used $\left(0.01 \mathrm{~mm} \mathrm{day}^{-1}\right.$ in Hill et al. (2015) vs. surface the $0 \mathrm{dBZ}$ in 2C-RAIN-PROFILE and 2C-PRECIP-COLUMN products). It is interesting to note that the sign of $S_{\text {I_CDNC }}$ at large LWP is different from that of $S_{\text {I_AI }}$ (Fig. 10b), which is not true for AMSR-E LWP (not shown). This warrants further investigation in the future. 

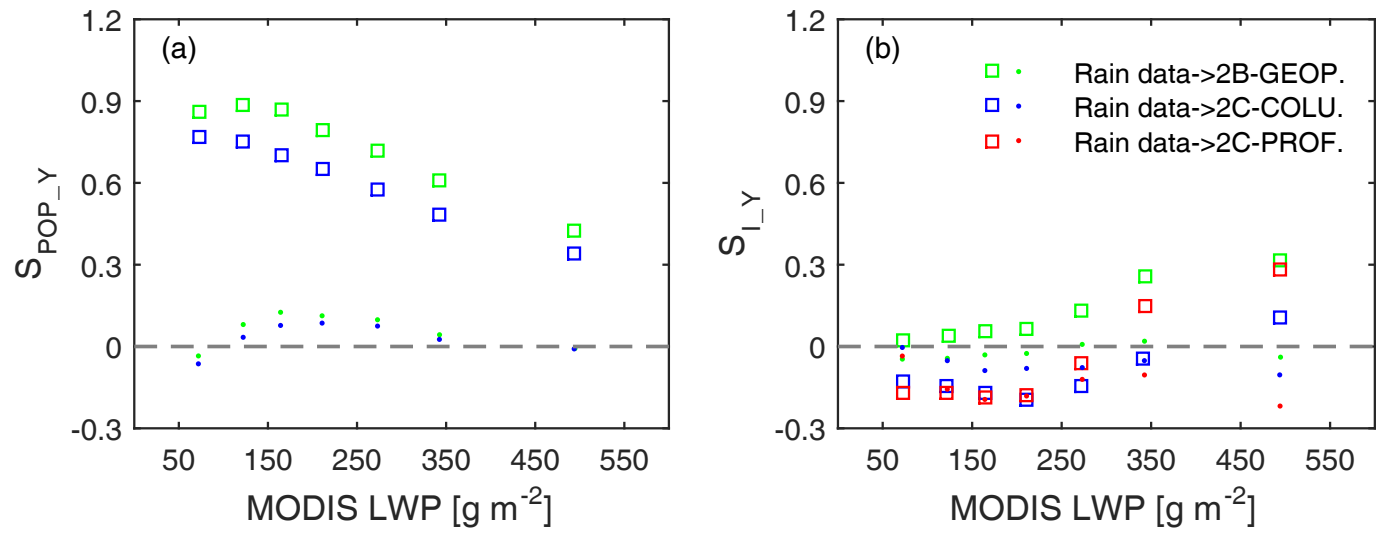

Figure 10. (a) $S_{\mathrm{POP} Y}$ and (b) $S_{\mathrm{I} Y \mathrm{Y}}$ as a function of MODIS LWP. The subscript Y denotes different aerosol proxies corresponding to $\mathrm{AI}$ (point) and $\mathrm{CDNC}$ (square). Different color symbols stand for different rain products: 2B-GEOPROF (2B-GEOP, green), 2C-PRECIPCOLUMN (2C-COLU, blue), and 2C-RAIN-PROFILE (2C-PROF, red). See text for further details.
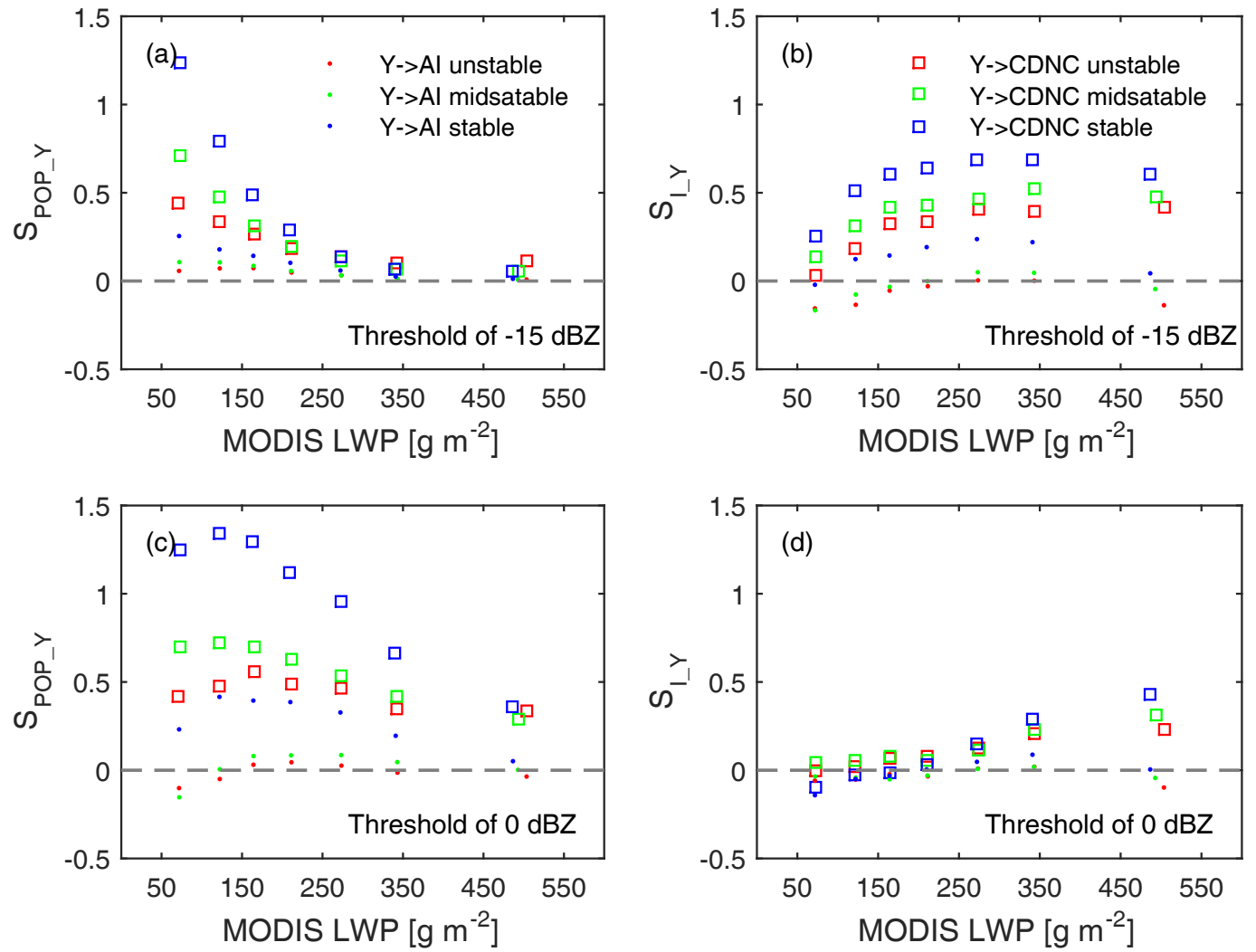

Figure 11. (a, c) S SOP_Y and (b, d) $S_{\text {I_Y }}$ as a function of MODIS LWP. The subscript Y denotes different aerosol proxies corresponding to AI (point) and CDNC (square). Blue, red, and green symbols stand for stable, unstable, and midstable regimes, respectively. Rain data come from 2B-GEOPROF. The top panels are for results based on the rain threshold of $-15 \mathrm{dBZ}$ and the bottom panels are based on the rain threshold of $0 \mathrm{dBZ}$.

\section{6 $S_{\mathbf{X}_{-} \mathbf{Y}}$ under different stability regimes}

Here, we examine precipitation susceptibility under different atmospheric stability regimes, as aerosol-cloudprecipitation interactions have been shown to differ under different stability regimes (e.g., L'Ecuyer et al., 2009; Zhang et al., 2016; Michibata et al., 2016). Based on the MODIS LWP and 2B-GEOPROF product with a $-15 \mathrm{dBZ}$ threshold, Fig. 11a and b suggest that both $S_{\mathrm{POP}}$ and $S_{\mathrm{I}}$ increase with a more stable environment. This pattern for $S_{\mathrm{POP}}$ is consis- 

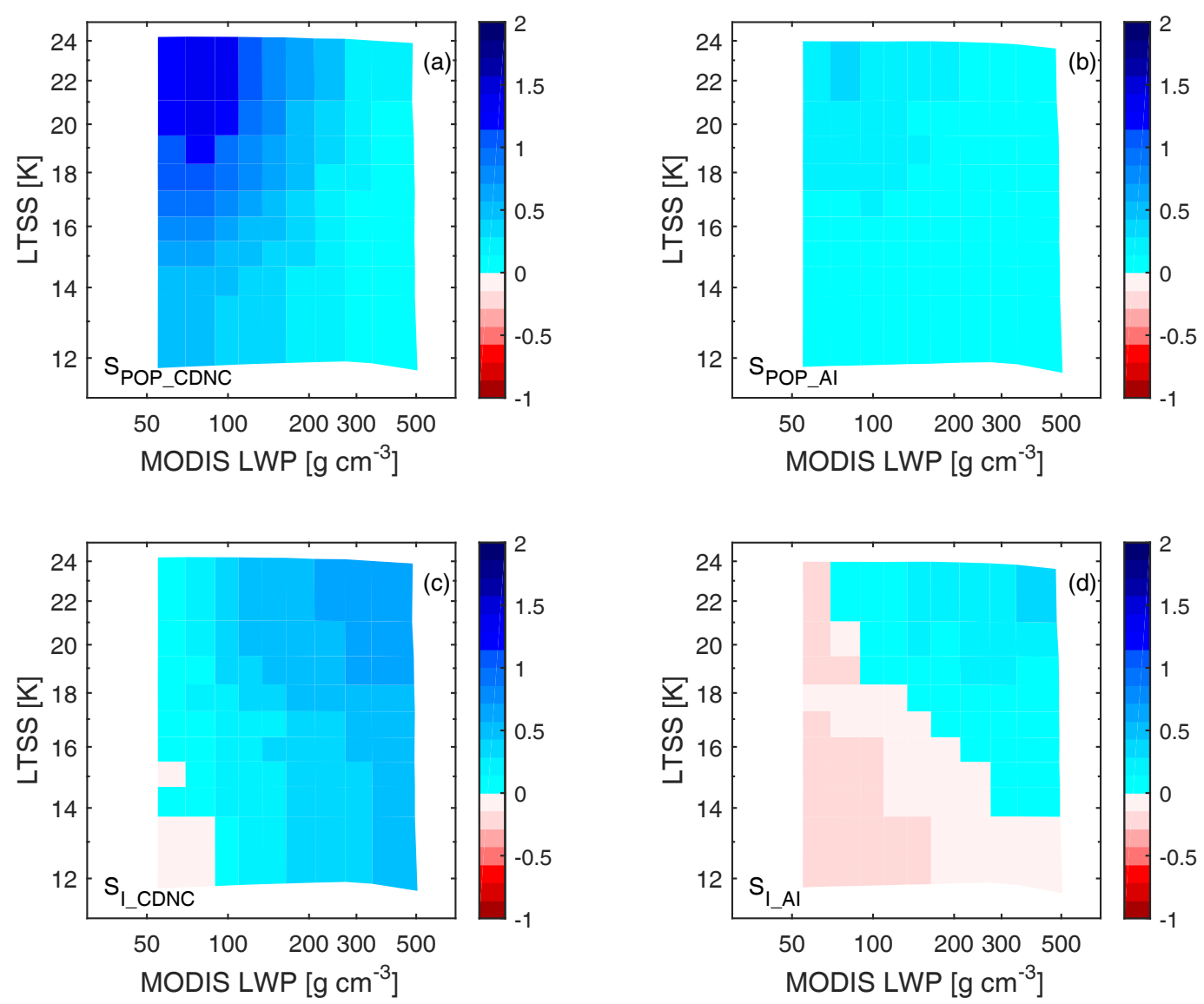

Figure 12. Distribution of (a-b) $S_{\text {POP_Y }}$ and (c-d) $S_{\text {I_Y }}$ as a function of MODIS LWP and LTSS. Rain data are from 2B-GEOPROF with a threshold of $-15 \mathrm{dBZ}$. Each LTSS bin contains on average the same amount of pixels.

tent with the findings of L'Ecuyer et al. (2009) who showed that suppression of precipitation was largest at lower LWP in stable environments. Terai et al. (2015) also found maximum $S_{\text {POP_CDNC occurred in regions where a stable regime was }}$ predominant. The distribution of the precipitation susceptibility with respect to LTSS and LWP shown in Fig. 12 using the $2 \mathrm{~B}-\mathrm{GEOPROF}$ product with the $-15 \mathrm{dBZ}$ rain threshold is consistent with Fig. 11a and b: $S_{\text {POP }}$ increases with increasing LTSS with the exception of high LWP. Although not shown here, SPOP_AI based on the 2C-PRECIP-COLUMN and AMSR-E LWP product produces a similar pattern with the result of (L'Ecuyer et al., 2009), who showed the slope between POP and AI is small both at low and high LWP, but this magnitude tends to increase at intermediate LWP and high LTSS.

Rain definition significantly affects spread of $S_{\text {POP }}$ and $S_{\mathrm{I}}$ under different stability regimes. As rain threshold increases, the discrepancy in $S_{\mathrm{POP}}$ among different LTSS conditions is more significant (Fig. 11c vs. a), while discrepancy in $S_{\mathrm{I}}$ becomes smaller. LTSS dependence of $S_{\mathrm{I}}$ is even reversed at low LWP with the $0 \mathrm{dBZ}$ threshold compared to that using the $-15 \mathrm{dBZ}$ threshold (Fig. 11d vs. b).
The abovementioned features of LTSS dependency are also true in terms of LWP-weighed mean value, as shown in Fig. 13. For all those cases based on different rain products and LWP products, the LWP-weighed mean of $S_{\mathrm{POP}}$ is generally larger under stable conditions compared with unstable conditions. Yet, this feature does not hold true for $S_{\mathrm{I}}$ except the case based on the 2B-GEOPROF data set with the $-15 \mathrm{dBZ}$ threshold. Our results also suggest that it is important to account for the influence of atmospheric stability due to the clear dependence of $S_{\mathrm{POP}}$ on metrics like LTSS, though it is acknowledged that LTSS alone is an imperfect metric for isolating cloud regimes (e.g., Nam and Quaas, 2013). Different metrics associated with cloud regimes should be examined in the future to better understand the effect of cloud regimes on precipitation susceptibility. For instance, LTSS can be combined with vertical pressure velocity to distinguish between different cloud types (Zhang et al., 2016).

\section{Discussion}

Figure 14 shows the range of precipitation susceptibility estimated from different LWP and rain products. Here, the 

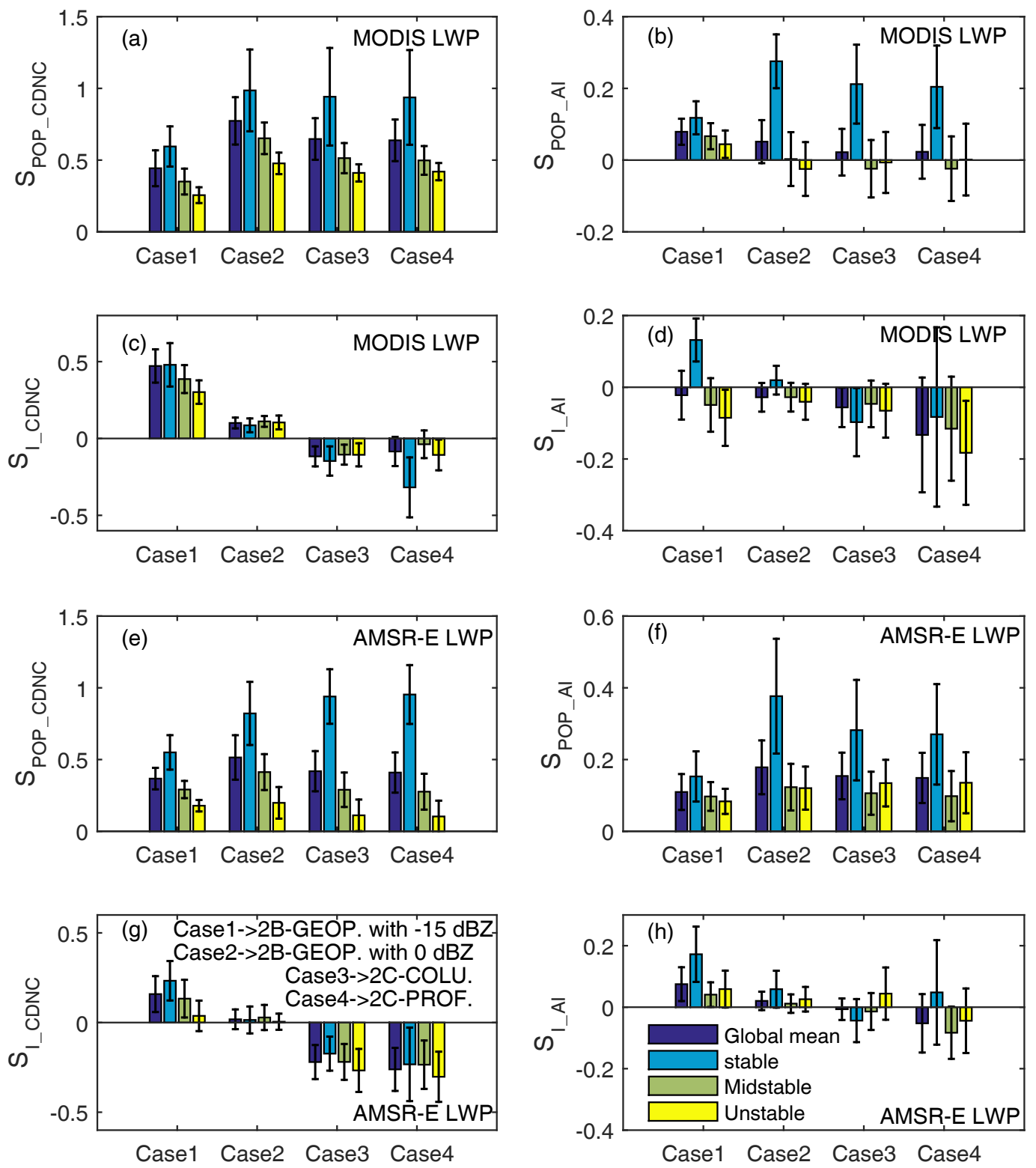

Figure 13. The LWP-weighed mean values of $(\mathbf{a}, \mathbf{b}, \mathbf{e}, \mathbf{f}) S_{\mathrm{POP}}$ and $(\mathbf{c}, \mathbf{d}, \mathbf{g}, \mathbf{h}) S_{\mathrm{I}}$ under different stability regimes for four cases. Case 1 and case 2 are both based on the 2B-GEOPROF product but use the threshold of -15 and $0 \mathrm{dBZ}$, respectively. Case 3 and case 4 use $2 \mathrm{C}$-PRECIPCOLUMN and 2C-RAIN-PROFILE products, respectively. The top two panels use MODIS LWP and the bottom two panels use AMSR-E LWP. Error bars are based on the LWP-weighed mean values of $95 \%$ confidence intervals for the susceptibility estimates.

threshold of $0 \mathrm{dBZ}$ of maximum radar reflectivity is used for the 2B-GEOPROF product and the rain certain flag is used for 2C-PRECIP-COLUMN and 2C-RAIN-PROFILE products. It shows that uncertainties in $S_{\text {POP }}$ (Fig. 14a) as a result of using different LWP and/or rain products are smaller than the uncertainties associated with $S_{\mathrm{I}}$ and $S_{\mathrm{R}}$ (Fig. 14b and c). The uncertainties in $S_{\text {POP }}$ are mainly attributed to different LWP products as described in Sect. 3.4 (see red symbols in Fig. 9a and c).
Our results may help to reconcile some of the differences in previous estimates of precipitation susceptibility. For example, our results show that $S_{\mathrm{X}_{-} \mathrm{AI}} \approx 0.3 S_{\mathrm{X}_{-} \mathrm{CDNC}}$ (Table 3 and Fig. 1), which explains why $S_{\text {POP CDNC in }}$ Terai et al. (2015) is much larger than $S_{\text {POP_AI }}$ in Wang et al. (2012). Previous studies are also different in how precipitation susceptibility varies with increasing LWP. Our results show that $S_{\text {I generally increases with LWP at low and }}$ moderate LWP and then decreases with increasing LWP at moderate and high LWP, consistent with results from 

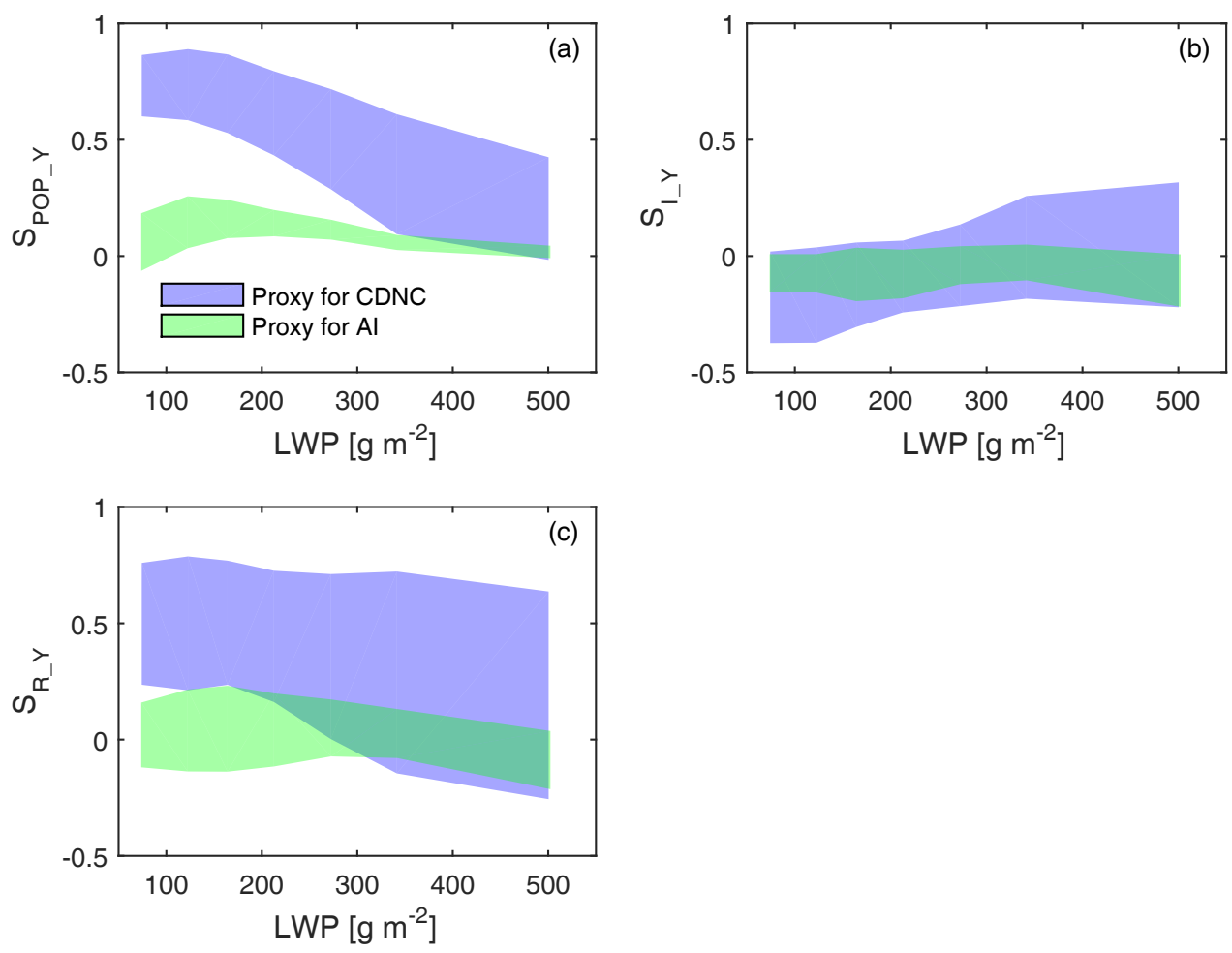

Figure 14. (a) $S_{\mathrm{POP} Y \mathrm{Y}}$, (b) $S_{\mathrm{I} \_\mathrm{Y}}$, and (c) $S_{\mathrm{R} \_\mathrm{Y}}$ as a function of LWP. The subscript Y denotes different aerosol proxies corresponding to AI (light green) and CDNC (light blue). Shade areas show the range of precipitation susceptibility from different rain products (same as Fig. 10) and different LWP products (MODIS and AMSR-E).

Feingold et al. (2013), Michibata et al. (2016), and Jung et al. (2016). The monotonic increase of $S_{I_{-} C D N C}$ with increasing LWP in Terai et al. (2015) is mainly because the LWP range in their study is relatively narrow (from 0 to $\sim 400 \mathrm{~g} \mathrm{~m}^{-2}$ ) and our results suggest that when the upper bound of LWP is extended to $\sim 800 \mathrm{~g} \mathrm{~m}^{-2}$, the "descending branch" (S decreases with increasing LWP) noted in Feingold et al. (2013) appears, though the exact LWP value where

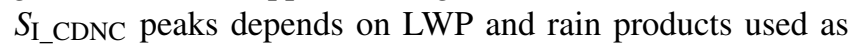
well as the rainfall threshold choices.

Interestingly, $S_{\text {I }}$ tends to be negative at low LWP both for AMSR-E and MODIS LWP (Fig. 5b). This is closely associated with positive correlation between conditionalmean rainfall intensity and CDNC (AI) at low LWP bins where $\mathrm{CDNC}(\mathrm{AI})$ is high (Fig. 7e-h). More negative values are captured when $S_{\mathrm{I}}$ is estimated using 2C-PRECIPCOLUMN and 2C-RAIN-PROFILE products and using high rainfall thresholds (Figs. 9b, d, 10b, and 13). Furthermore, based on these rain products, $S_{\text {I_CDNC }}$ is all negative at low and intermediate LWP regardless of the LWP data set used (Fig. 10b) and almost all of mean $S_{\text {I_CDNC is significantly }}$ negative regardless of stability regimes (Fig. 13). Depending on the LWP products adopted, using AI instead of CDNC in estimating $S_{\text {I }}$ can make it less negative (for AMSR-E LWP) or more negative (for MODIS LWP) (Fig. 13). Terai et al. (2015) also found negative values of $S_{I_{-} C D N C}$ at low LWP and high CDNC. In their study, the sign and/or magnitude of $S_{\text {I_CDNC }}$ at low LWP are distinct across different regions. In addition, Koren et al. (2014) found a positive relationship between AOD and rain rate over pristine areas with warm and aerosol-limited clouds, which was attributed to aerosol invigoration effect. As $S_{\text {I }}$ shows large differences under different stability regimes (Fig. 13), it would be highly interesting to analyze regional variation in $S_{\mathrm{I}}$ to further understand negative $S_{\mathrm{I}}$ in the future, especially under unstable regimes.

Furthermore, our results show that drizzle intensity is more susceptible to aerosol perturbations than rain intensity (see Fig. 9b and d), which might help to explain why negative values of $S_{\text {I_CDNC }}$ occur more frequently with increasing rainfall thresholds. Jung et al. (2016) found more negative values of $S_{\text {I_CDNC }}$ with increasing threshold (see Fig. B2 in Jung et al., 2016). In addition, rain products used in our study are all derived from CPR aboard CloudSat. With increasing thresholds, rainfall becomes heavy and uncertainty in rain rate retrieval can grow as CPR is insensitive to heavy precipitation (Haynes et al., 2009). Thus, a combination of different rain satellite products (e.g., CloudSat and the Tropical Rainfall Measuring Mission - TRMM) would be helpful for better understanding negative $S_{\mathrm{I}}$. 
It should be noted that precipitation susceptibility in our study is based on Eq. (6) and is derived by linear regression between precipitation fields and CDNC/AI in log-log space. The negative/positive correlation between precipitation frequency/intensity and aerosols may not be readily explained like aerosol effects on precipitation. For example, a negative correlation between precipitation frequency and aerosols may come from the wet scavenging effects of aerosols (more precipitation leads to less aerosols) but not aerosol suppression of precipitation. However, in our study, we not only calculate precipitation susceptibility with respect to AI ( $\left.S_{\mathrm{X} \_\mathrm{AI}}\right)$ but also with respect to $\mathrm{CDNC}\left(S_{\mathrm{X}} \mathrm{CDNC}\right)$, and the latter is expected to be less affected by the wet scavenging effects. The broad consistency between these two estimates shown in our results (Fig. 13), especially for the estimate of $S_{\mathrm{POP}}$, lends support to the limited influence of wet scavenging in our estimate. Further support for this comes from the fact that precipitation susceptibility estimates based on the $1^{\circ} \mathrm{L} 3$ MODIS aerosol products are similar to those based on the $10 \mathrm{~km} \mathrm{L2}$ MODIS aerosol products (Fig. 4); as we would expect, the wet scavenging effects are more important at smaller scales if the wet scavenging effects are a dominating factor. Nevertheless, the effects of wet scavenging can still be important in satellite studies of aerosol-cloud-precipitation interactions and should be better quantified in future, perhaps in combination with model simulations.

\section{Summary}

In this paper, we estimate precipitation susceptibility on warm clouds over global oceans based on multi-sensor aerosol and cloud products from the A-Train satellites, including MODIS, AMSR-E, CALIOP, and CPR observations, covering the period June 2006 to April 2011. In addition to different aerosol, cloud, and rain products, we also analyze other factors that have potential influence on susceptibility, such as different definitions of precipitation susceptibility (six different susceptibilities defined by Eq. 6), stability regimes, and different thresholds for defining a rain event (i.e., -15 and $0 \mathrm{dBZ}$ of maximum radar reflectivity for $2 \mathrm{~B}$ GEOPROF). The primary goal of the study is to quantify uncertainties in precipitation susceptibility estimates from satellite observations.

In general, $S_{\mathrm{POP}}$ is a relatively robust metric throughout different LWP and rain products, and its estimate is less sensitive to different data sets used (Figs. 13 and 14). SPOP_CDNC shows overall a monotonic decreasing trend with respect to LWP. SPOP_AI increases to a maximum at low LWP and then decreases with higher LWP. In contrast, $S_{\text {I }}$ differs considerably among different LWP and rain products (Figs. 13 and 14). Interestingly, $S_{\text {I_CDNC }}$ and $S_{\text {I_AI }}$ differ between those LWP products with the opposite pattern: $S_{\text {I_CDNC }}$ based on MODIS LWP is higher than that using AMSR-E LWP and the reverse is true for $S_{\text {I_AI }}$ (Fig. 13). Negative $S_{\mathrm{I}}$ is found in our study, especially at low LWP. However, the extent of negative $S_{\mathrm{I}}$ depends on LWP and rain products, rainfall thresholds, and whether $S_{\mathrm{I}}$ is calculated with respect to AI or CDNC (Fig. 13). More negative values are found when $S_{\text {I }}$ is calculated based on 2C-PRECIP-COLUMN and 2C-RAINPROFILE products, and $S_{\mathrm{I}}$ based on rain samples (with a $0 \mathrm{dBZ}$ threshold) tends to be more negative. Further studies (regional variation in $S_{\text {I }}$, combination of different rain satellite products, etc.) are needed to understand this issue.

Precipitation susceptibility for drizzle (with a $-15 \mathrm{dBZ}$ rainfall threshold) is significantly different from that for rain (with a $0 \mathrm{dBZ}$ rainfall threshold) (Figs. 9 and 13). Our results suggest that onset of drizzle is not as readily suppressed by increases in AI or CDNC in warm clouds as rainfall (i.e., $S_{\mathrm{POP}}$ is smaller for drizzle than for rain, especially at moderate LWP; Fig. 9). This may partly come from the fact that POP of drizzle is close to $100 \%$ at moderate and high LWP regardless of CDNC or AI values (Fig. 7a-d), which makes it insensitive to perturbations in CDNC or AI and results in smaller $S_{\text {POP }}$ at these LWP bins compared with $S_{\text {POP }}$ for rain (Fig. 9). On the other hand, precipitation intensity susceptibility is generally smaller for rain than for drizzle. This is consistent with our expectation that when precipitation intensity increases, accretion contributes more to the production of precipitation, which makes precipitation intensity less sensitive to perturbation in CDNC or AI, as accretion is less dependent on CDNC compared with autoconversion (Feingold et al., 2013; Wood, 2005). In addition, the extent of these differences between drizzle and rain depends on the LWP products used.

$S_{\mathrm{X} \_ \text {AI }}$ based on aerosol products at different spatial resolutions (i.e., $10 \mathrm{~km}$ vs. $1^{\circ}$ ) is consistent with the others. Chen et al. (2014) also found that aerosol indirect forcing derived from satellite observations was similar from AI observations at different resolutions (i.e., $20 \mathrm{~km}$ vs. $1^{\circ}$ ). This suggests that aerosol layers over oceans are relatively homogeneous, implying that aerosol properties at coarse resolution may be suitable for studying aerosol-cloud interactions over oceans.

$S_{\text {POP }}$ strongly depends on LTSS, with larger values under a more stable environment. This dependence is evident over all LWP bins, especially at low and moderate LWP bins, and is more significant for rain than for drizzle (Figs. 11 and 13). These features, however, are less robust for $S_{\text {I }}$ throughout different LWP and rain products, as $S_{\text {I }}$ estimates show large uncertainties from different data sets (Fig. 13). Only in the case of $S_{\text {I }}$ estimated from the 2B-GEOPROF product for drizzle (with a $-15 \mathrm{dBZ}$ threshold) does the LTSS dependence of $S_{\text {I }}$ hold for both MODIS and AMSR-E LWP. The pattern of $S_{\text {POP_AI }}$ under different stability conditions from our paper (Fig. 13b and f) is consistent with the findings of L'Ecuyer et al. (2009). In addition, Terai et al. (2015) found that maximum $S_{\text {POP_CDNC occurred in regions where a stable regime is }}$ predominant. Lebo and Feingold (2014) calculated precipitation susceptibility for stratocumulus and trade wind cumulus clouds using large eddy simulations (LESs) and included an 
overview of precipitation susceptibility estimates based on LESs in the literature. However, their results focus on the relationship between precipitation susceptibility and cloud water response to aerosol perturbations, and did not examine how precipitation susceptibility might be different for clouds under different cloud regimes. The physical mechanisms behind the strong dependence of $S_{\text {POP }}$ on stability are still unclear and warrant further investigation in the future.

The results presented here show that the discrepancy in magnitude between $S_{\mathrm{X} \_ \text {AI }}$ and $S_{\mathrm{X} \_ \text {CDNC }}$ can be mainly attributed to the dependency of CDNC on AI. On the global scale, our results show that $S_{\mathrm{X} \_\mathrm{AI}}$ is about one-third of $S_{\mathrm{X} \_C D N C}$. This relationship is more applicable to $S_{\mathrm{POP}}$ and is less applicable to $S_{\mathrm{I}}$. In addition, $S_{\mathrm{R}} \approx S_{\mathrm{I}}+S_{\mathrm{POP}}$ is generally true for different LWP products and over different LTSS conditions.

As $S_{\text {POP }}$ demonstrates relatively robust features across different LWP and rain products, this makes it a valuable metric for quantifying aerosol-cloud-precipitation interactions in observations and models. For instance, it would be highly interesting to examine why $S_{\mathrm{POP}}$ strongly depends on atmospheric stability and how well this dependence is represented in a hierarchy of models (e.g., large eddy simulations, cloud resolving models, regional climate models, and global climate models). We also note that $S_{\text {POP_CDNC }}$ is generally less uncertain compared to $S_{\text {POP_AI }}$ and that a relatively robust relationship between $S_{\text {POP_CDNC }}$ and $S_{\text {POP_AI }}$ exists (i.e., $S_{\mathrm{X}_{-} \mathrm{AI}} \approx 0.3 S_{\mathrm{X} \_\mathrm{CDNC}}$ ) (Fig. 13 and Table 3 ). Given that aerosol retrievals near clouds are still challenging and aerosol-cloud relationships in satellite observations can be affected by aerosol retrieval contaminations from clouds, we recommend to first thoroughly quantify $S_{\mathrm{POP}_{-} \mathrm{CDNC}}$ in observations and models. As $S_{\text {POP_CDNC }}$ is derived based on CDNC instead of AI, $S_{\text {POP_CDNC }}$ is also not influenced by wet scavenging. Only after $S_{\text {POP_CDNC }}$ is thoroughly quantified, can we then combine it with CDNC dependence on AI to better quantify $S_{\text {POP_AI }}$.

On the other hand, $S_{\text {I }}$ estimates strongly depend on satellite retrieval products. Uncertainties in $S_{\text {I }}$ estimate are particularly large when $S_{\mathrm{I}}$ is estimated based on rain samples ( $>0 \mathrm{dBZ})$ rather than drizzle samples $(>-15 \mathrm{dBZ})$. It would then be desirable to use drizzle samples to estimate $S_{\mathrm{I}}$. However, satellite retrieval of the precipitation rate for drizzle can be highly uncertain. It is therefore recommended to further improve the retrieval accuracy of the precipitation rate for drizzle in satellite observations in order to better use satellite estimates of $S_{I}$ to quantify aerosol-cloud precipitation interactions. Alternatively, long-term ground and in situ observations with high-accuracy precipitation rate retrievals can be used to provide better estimate $S_{\mathrm{I}}$ and to further quantify aerosol-cloud-precipitation interactions.

Data availability. MYD08_D3 and MYD04_L2 products are available through LAADS, the Level 1 and Atmosphere Archive and Distribution System (http://ladsweb.nascom.nasa.gov/). MYD06_L2 and 2B-GEOPROF data, both collocated to CALIOP subtrack, are obtained from the ICARE Data and Services Center (http://www.icare.univ-lille1.fr/projects/calxtract/products). 2C-PRECIP-COLUMN and 2C-RAIN-PROFILE data sets are available from the CloudSat Data Processing Center (http: //cloudsat.atmos.colostate.edu/data). CAL_LID_L2_05kmALay data are obtained from the Atmospheric Science Data Center (ASDC; https://eosweb.larc.nasa.gov). The AMSR-E/Aqua L2B Global Swath Ocean product can be obtained from the NASA Distributed Active Archive Center (DAAC) at NSIDC (http://nsidc.org/daac).

Competing interests. The authors declare that they have no conflict of interest.

Acknowledgements. Minghuai Wang was supported by the National Natural Science Foundation of China (41575073 and 41621005) and by the Jiangsu Province specially appointed professorship grant, the One Thousand Young Talents Program. We thank Johannes Quaas and an anonymous reviewer for their constructive comments, which allowed us to further improve the manuscript.

Edited by: Michael Schulz

Reviewed by: Johannes Quaas and one anonymous referee

\section{References}

Anderson, T. L., Charlson, R. J., Winker, D. M., Ogren, J. A., and Holmén, K.: Mesoscale variations of tropospheric aerosols, J. Atmos. Sci., 60, 119-136, https://doi.org/10.1175/15200469(2003)060<0119:MVOTA>2.0.CO;2, 2003.

Bennartz, R.: Global assessment of marine boundary layer cloud droplet number concentration from satellite, J. Geophys. Res.Atmos., 112, D02201, https://doi.org/10.1029/2006JD007547, 2007.

Boucher, O., Randall, D., Artaxo, P., Bretherton, C., Feingold, G., Forster, P., Kerminen, V.-M., Kondo, Y., Liao, H., Lohmann, U., Rasch, P., Satheesh, S. K., Sherwood, S., Stevens, B., and Zhang, X. Y.: Clouds and aerosols, in: Climate Change 2013: The Physical Science Basis. Contribution of Working Group I to the Fifth Assessment Report of the Intergovernmental Panel on Climate Change, edited by: Stocker, T. F., Qin, D., Plattner, G.K., Tignor, M., Allen, S. K., Boschung, J., Nauels, A., Xia, Y., Bex, V., and Midgley, P. M., Cambridge University Press, Cambridge, UK and New York, NY, USA, 2013.

Bréon, F. M., Vermeulen, A., and Descloitres, J.: An evaluation of satellite aerosol products against sunphotometer measurements, Remote Sens. Environ., 115, 3102-3111, https://doi.org/10.1016/j.rse.2011.06.017, 2011.

Chand, D., Wood, R., Ghan, S. J., Wang, M., Ovchinnikov, M., Rasch, P. J., Miller, S., Schichtel, B., and Moore, T.: Aerosol optical depth increase in partly cloudy conditions, J. Geophys. Res.Atmos., 117, d17207, https://doi.org/10.1029/2012JD017894, 2012. 
Chen, Y.-C., Christensen, M. W., Stephens, G. L., and Seinfeld, J. H.: Satellite-based estimate of global aerosol-cloud radiative forcing by marine warm clouds, Nat. Geosci., 7, 643-646, https://doi.org/10.1038/ngeo2214, 2014.

Cho, H.-M., Zhang, Z., Meyer, K., Lebsock, M., Platnick, S., Ackerman, A. S., Di Girolamo, L., C.-Labonnote, L., Cornet, C., Riedi, J., and Holz, R. E.: Frequency and causes of failed MODIS cloud property retrievals for liquid phase clouds over global oceans, J. Geophys. Res.-Atmos., 120, 4132-4154, https://doi.org/10.1002/2015JD023161, 2015.

Christensen, M. W., Neubauer, D., Poulsen, C. A., Thomas, G. E., McGarragh, G. R., Povey, A. C., Proud, S. R., and Grainger, R. G.: Unveiling aerosol-cloud interactions - Part 1: Cloud contamination in satellite products enhances the aerosol indirect forcing estimate, Atmos. Chem. Phys., 17, 13151-13164, https://doi.org/10.5194/acp-17-13151-2017, 2017.

Comstock, K. K., Wood, R., Yuter, S. E., and Bretherton, C. S.: Reflectivity and rain rate in and below drizzling stratocumulus, Q. J. Roy. Meteor. Soc., 130, 2891-2918, https://doi.org/10.1256/qj.03.187, 2004.

Costantino, L. and Bréon, F. M.: Analysis of aerosol-cloud interaction from multi-sensor satellite observations, Geophys. Res. Lett., 37, 1-5, https://doi.org/10.1029/2009GL041828, 2010.

Duong, H. T., Sorooshian, A., and Feingold, G.: Investigating potential biases in observed and modeled metrics of aerosol-cloudprecipitation interactions, Atmos. Chem. Phys., 11, 4027-4037, https://doi.org/10.5194/acp-11-4027-2011, 2011.

Feingold, G. and Siebert, H.: Cloud-Aerosol Interactions from the Micro to the Cloud Scale, MIT Press, Cambridge, MA, 319-338, 2009.

Feingold, G., McComiskey, A., Rosenfeld, D., and Sorooshian, A.: On the relationship between cloud contact time and precipitation susceptibility to aerosol, J. Geophys. Res.-Atmos., 118, 1054410554, https://doi.org/10.1002/jgrd.50819, 2013.

Ghan, S., Wang, M., Zhang, S., Ferrachat, S., Gettelman, A., Griesfeller, J., Kipling, Z., Lohmann, U., Morrison, H., Neubauer, D., Partridge, D. G., Stier, P., Takemura, T., Wang, H., and Zhang, K.: Challenges in constraining anthropogenic aerosol effects on cloud radiative forcing using present-day spatiotemporal variability, P. Natl. Acad. Sci. USA, 113, 5804-5811, https://doi.org/10.1073/pnas.1514036113, 2016.

Greenwald, T. J.: A 2 year comparison of AMSR-E and MODIS cloud liquid water path observations, Geophys. Res. Lett., 36, 2-7, https://doi.org/10.1029/2009GL040394, 2009.

Greenwald, T. J., L'Ecuyer, T. S., and Christopher, S. A.: Evaluating specific error characteristics of microwave-derived cloud liquid water products, Geophys. Res. Lett., 34, L22807, https://doi.org/10.1029/2007GL031180, 2007.

Gryspeerdt, E., Quaas, J., and Bellouin, N.: Constraining the aerosol influence on cloud fraction, J. Geophys. Res.-Atmos., 121, 35663583, https://doi.org/10.1002/2015JD023744, 2016.

Haynes, J. M., L'Ecuyer, T. S., Stephens, G. L., Miller, S. D., Mitrescu, C., Wood, N. B., and Tanelli, S.: Rainfall retrieval over the ocean with spaceborne W-band radar, J. Geophys. Res.Atmos., 114, D00A22, https://doi.org/10.1029/2008JD009973, 2009

Hill, A. A., Shipway, B. J., and Boutle, I. A.: How sensitive are aerosol-precipitation interactions to the warm rain representation?, J. Adv. Model. Earth Sy., 7, 987-1004 https://doi.org/10.1002/2014MS000422, 2015.

Horváth, Á. and Gentemann, C.: Cloud-fraction-dependent bias in satellite liquid water path retrievals of shallow, nonprecipitating marine clouds, Geophys. Res. Lett., 34, L22806, https://doi.org/10.1029/2007GL030625, 2007.

Hubanks, P., Platnick, S., King, M., and Ridgway, B.: MODIS Atmosphere L3 Gridded Product Algorithm Theoretical Basis Document (ATBD) \& Users Guide, Collection 006, Version 4.2., NASA-GSFC, Greenbelt, Md., available at: https: //modis-images.gsfc.nasa.gov/_docs/L3_ATBD_C6.pdf (last access: 3 February 2018), 1, 2016.

Jung, E., Albrecht, B. A., Sorooshian, A., Zuidema, P., and Jonsson, H. H.: Precipitation susceptibility in marine stratocumulus and shallow cumulus from airborne measurements, Atmos. Chem. Phys., 16, 11395-11413, https://doi.org/10.5194/acp-1611395-2016, 2016.

Kaufman, Y. J., Tanré, D., Remer, L. A., Vermote, E. F., Chu, A., and Holben, B. N.: Operational remote sensing of tropospheric aerosol over land from EOS moderate resolution imaging spectroradiometer, J. Geophys. Res., 102, 17051-17067, https://doi.org/10.1029/96JD03988, 1997.

Kim, M. H., Kim, S. W., Yoon, S. C., and Omar, A. H.: Comparison of aerosol optical depth between CALIOP and MODIS-Aqua for CALIOP aerosol subtypes over the ocean, J. Geophys. Res.-Atmos., 118, 13241-13252, https://doi.org/10.1002/2013JD019527, 2013.

King, J. M., Kummerow, C. D., van den Heever, S. C., and Igel, M. R.: Observed and modeled warm rainfall occurrence and its relationships with cloud macrophysical properties, J. Atmos. Sci., 72, 4075-4090, https://doi.org/10.1175/JAS-D-14-0368.1, 2015.

Kittaka, C., Winker, D. M., Vaughan, M. A., Omar, A., and Remer, L. A.: Intercomparison of column aerosol optical depths from CALIPSO and MODIS-Aqua, Atmos. Meas. Tech., 4, 131-141, https://doi.org/10.5194/amt-4-131-2011, 2011.

Klein, S. A. and Hartmann, D. L.: The seasonal cycle of low stratiform clouds, J. Climate, 6, 1587-1606, https://doi.org/10.1175/1520 0442(1993)006<1587:TSCOLS>2.0.CO;2, 1993.

Koren, I., Dagan, G., and Altaratz, O.: From aerosol-limited to invigoration of warm convective clouds, Science, 344, 1143-1146, https://doi.org/10.1126/science.1252595, 2014.

Kubar, T. L., Hartmann, D. L., and Wood, R.: Understanding the importance of microphysics and macrophysics for warm rain in marine low clouds. Part I: Satellite observations, J. Atmos. Sci., 66, 2953-2972, https://doi.org/10.1175/2009JAS3071.1, 2009.

Lebo, Z. J. and Feingold, G.: On the relationship between responses in cloud water and precipitation to changes in aerosol, Atmos. Chem. Phys., 14, 11817-11831, https://doi.org/10.5194/acp-1411817-2014, 2014.

Lebsock, M. D. and L'Ecuyer, T. S.: The retrieval of warm rain from CloudSat, J. Geophys. Res.-Atmos., 116, 1-14, https://doi.org/10.1029/2011JD016076, 2011.

L'Ecuyer, T. S. and Jiang, J. H.: Touring the atmosphere aboard the A-Train, Phys. Today, 63, 36-41, https://doi.org/10.1063/1.3653856, 2010.

L'Ecuyer, T. S., Berg, W., Haynes, J., Lebsock, M., and Takemura, T.: Global observations of aerosol impacts on precipitation 
occurrence in warm maritime clouds, J. Geophys. Res.-Atmos., 114, 1-15, https://doi.org/10.1029/2008JD011273, 2009.

Levy, R. C., Mattoo, S., Munchak, L. A., Remer, L. A., Sayer, A. M., Patadia, F., and Hsu, N. C.: The Collection 6 MODIS aerosol products over land and ocean, Atmos. Meas. Tech., 6, 29893034, https://doi.org/10.5194/amt-6-2989-2013, 2013.

Ma, X., Bartlett, K., Harmon, K., and Yu, F.: Comparison of AOD between CALIPSO and MODIS: significant differences over major dust and biomass burning regions, Atmos. Meas. Tech., 6, 2391-2401, https://doi.org/10.5194/amt-6-2391-2013, 2013.

Mann, J. A. L., Chiu, J. C., Hogan, R. J., Oconnor, E. J., Lecuyer, T. S., Stein, T. H. M., and Jefferson, A.: Aerosol impacts on drizzle properties in warm clouds from ARM Mobile Facility maritime and continental deployments, J. Geophys. Res., 119, 4136-4148, https://doi.org/10.1002/2013JD021339, 2014.

Marchand, R., Mace, G. G., Ackerman, T., and Stephens, G.: Hydrometeor detection using Cloudsat - an earth-orbiting 94-GHz cloud radar, J. Atmos. Ocean. Tech., 25, 519-533, https://doi.org/10.1175/2007JTECHA1006.1, 2008.

McComiskey, A. and Feingold, G.: The scale problem in quantifying aerosol indirect effects, Atmos. Chem. Phys., 12, 1031-1049, https://doi.org/10.5194/acp-12-1031-2012, 2012.

Michibata, T., Suzuki, K., Sato, Y., and Takemura, T.: The source of discrepancies in aerosol-cloud-precipitation interactions between GCM and A-Train retrievals, Atmos. Chem. Phys., 16, 15413-15424, https://doi.org/10.5194/acp-16-154132016, 2016.

Miller, D. J., Zhang, Z., Ackerman, A. S., Platnick, S., and Baum, B. A.: The impact of cloud vertical profile on liquid water path retrieval based on the bispectral method: A theoretical study based on large-eddy simulations of shallow marine boundary layer clouds, J. Geophys. Res.-Atmos., 121, 4122-4141, https://doi.org/10.1002/2015JD024322, 2016.

Mülmenstädt, J., Sourdeval, O., Delanoë, J., and Quaas, J.: Frequency of occurrence of rain from liquid-, mixed-, and ice-phase clouds derived from A-Train satellite retrievals, Geophys. Res. Lett., 42, 6502-6509, https://doi.org/10.1002/2015GL064604, 2015.

Nakajima, T., Higurashi, A., Kawamoto, K., and Penner, J. E.: A possible correlation between satellite-derived cloud and aerosol microphysical parameters, Geophys. Res. Lett., 28, 1171-1174, https://doi.org/10.1029/2000GL012186, 2001.

Nam, C. C. W. and Quaas, J.: Geographically versus dynamically defined boundary layer cloud regimes and their use to evaluate general circulation model cloud parameterizations, Geophys. Res. Lett., 40, 4951-4956, https://doi.org/10.1002/grl.50945, 2013.

Platnick, S. and Twomey, S.: Determining the susceptibility of cloud albedo to changes in droplet concentration with the Advanced Very High Resolution Spectrometer, J. Appl. Meteorol., 33, 334-347, https://doi.org/10.1175/15200450(1994)033<0334:DTSOCA>2.0.CO;2, 1994

Platnick, S., King, M. D., Ackerman, S. A., Menzel, W. P., Baum, B. A., Riédi, J. C., and Frey, R. A.: The MODIS cloud products: Algorithms and examples from terra, IEEE T. Geosci. Remote, 41, 459-472, https://doi.org/10.1109/TGRS.2002.808301, 2003.

Platnick, S., Meyer, K. G., King, M. D., Wind, G., Amarasinghe, N., Marchant, B., Arnold, G. T., Zhang, Z., Hubanks, P. A.,
Holz, R. E., Yang, P., Ridgway, W. L., and Riedi, J.: The MODIS cloud optical and microphysical products: collection 6 updates and examples from Terra and Aqua, IEEE T. Geosci. Remote, 55, 502-525, https://doi.org/10.1109/TGRS.2016.2610522, 2017.

Quaas, J., Boucher, O., and Lohmann, U.: Constraining the total aerosol indirect effect in the LMDZ and ECHAM4 GCMs using MODIS satellite data, Atmos. Chem. Phys., 6, 947-955, https://doi.org/10.5194/acp-6-947-2006, 2006.

Seethala, C. and Horváth, Á.: Global assessment of AMSR$\mathrm{E}$ and MODIS cloud liquid water path retrievals in warm oceanic clouds, J. Geophys. Res.-Atmos., 115, 1-19, https://doi.org/10.1029/2009JD012662, 2010.

Sorooshian, A., Feingold, G., Lebsock, M. D., Jiang, H., and Stephens, G. L.: On the precipitation susceptibility of clouds to aerosol perturbations, Geophys. Res. Lett., 36, L13803, https://doi.org/10.1029/2009GL038993, 2009.

Stephens, G. L., Vane, D. G., Boain, R. J., Mace, G. G., Sassen, K., Wang, Z., Illingworth, A. J., O'Connor, E. J., Rossow, W. B., Durden, S. L., Miller, S. D., Austin, R. T., Benedetti, A., and Mitrescu, C.: The cloudsat mission and the A-Train: A new dimension of space-based observations of clouds and precipitation, B. Am. Meteorol. Soc., 83, 1771-1790, https://doi.org/10.1175/BAMS-83-12-1771, 2002.

Szczodrak, M., Austin, P. H., and Krummel, P. B.: Variability of optical depth and effective radius in marine stratocumulus clouds, $\mathrm{J}$ Atmos. Sci., 58, 2912-2926, https://doi.org/10.1175/15200469(2001)058<2912:VOODAE>2.0.CO;2, 2001.

Tackett, J. L. and Di Girolamo, L.: Enhanced aerosol backscatter adjacent to tropical trade wind clouds revealed by satellite-based lidar, Geophys. Res. Lett., 36, 1-5, https://doi.org/10.1029/2009GL039264, 2009.

Tanré, D., Kaufman, Y. J., Herman, M., and Mattoo, S.: Remote sensing of aerosol properties over oceans using the MODIS/EOS spectral radiances, J. Geophys. Res.-Atmos., 102, 16971-16988, https://doi.org/10.1029/96JD03437, 1997.

Terai, C. R., Wood, R., Leon, D. C., and Zuidema, P.: Does precipitation susceptibility vary with increasing cloud thickness in marine stratocumulus?, Atmos. Chem. Phys., 12, 4567-4583, https://doi.org/10.5194/acp-12-4567-2012, 2012.

Terai, C. R., Wood, R., and Kubar, T. L.: Satellite estimates of precipitation susceptibility in low-level marine stratiform clouds, J. Geophys. Res.-Atmos., 120, 8878-8889, https://doi.org/10.1002/2015JD023319, 2015.

Vaughan, M. a, Young, S., Winker, D. M., Powell, K., Omar, a, Liu, Z., Hu, Y., and Hostetler, C.: Fully automated analysis of space-based lidar data: an overview of the CALIPSO retrieval algorithms and data products, Proc. SPIE, 5575, 16-30, https://doi.org/10.1117/12.572024, 2004.

Wang, M., Ghan, S., Liu, X., L'Ecuyer, T. S., Zhang, K., Morrison, H., Ovchinnikov, M., Easter, R., Marchand, R., Chand, D., Qian, Y., and Penner, J. E.: Constraining cloud lifetime effects of aerosols using A-Train satellite observations, Geophys. Res. Lett., 39, L15709, https://doi.org/10.1029/2012GL052204, 2012.

Wentz, F. and Meissner, T.: AMSR Ocean Algorithm Theoretical Basis Document (ATBD), RSS Tech. Doc, Santa Rosa, CA, 2000 .

Wentz, F. and Meissner, T.: AMSR-E/Aqua L2B Global Swath Ocean Products derived from Wentz Algorithm. Version 2. NASA National Snow and Ice Data Center Dis- 
tributed Active Archive Center, Boulder, Colorado USA, https://doi.org/10.5067/AMSR-E/AE_OCEAN.002, 2004.

Wood, R.: Drizzle in stratiform boundary layer clouds. Part II: Microphysical aspects, J. Atmos. Sci., 62, 3034-3050, https://doi.org/10.1175/JAS3530.1, 2005.

Young, S. A. and Vaughan, M. A.: The retrieval of profiles of particulate extinction from Cloud-Aerosol Lidar Infrared Pathfinder Satellite Observations (CALIPSO) data: algorithm description, J. Atmos. Ocean. Tech., 26, 1105-1119, https://doi.org/10.1175/2008JTECHA1221.1, 2009.
Zhang, S., Wang, M., Ghan, S. J., Ding, A., Wang, H., Zhang, K., Neubauer, D., Lohmann, U., Ferrachat, S., Takeamura, T., Gettelman, A., Morrison, H., Lee, Y., Shindell, D. T., Partridge, D. G., Stier, P., Kipling, Z., and Fu, C.: On the characteristics of aerosol indirect effect based on dynamic regimes in global climate models, Atmos. Chem. Phys., 16, 2765-2783, https://doi.org/10.5194/acp-16-2765-2016, 2016.

Zhang, Z. and Platnick, S.: An assessment of differences between cloud effective particle radius retrievals for marine water clouds from three MODIS spectral bands, J. Geophys. Res.-Atmos., 116, d20215, https://doi.org/10.1029/2011JD016216, 2011. 